Review Article

\title{
Chitosan-Based Coating with Antimicrobial Agents: Preparation, Property, Mechanism, and Application Effectiveness on Fruits and Vegetables
}

\author{
Yage Xing, ${ }^{1}$ Qinglian Xu, ${ }^{1}$ Xingchen Li, ${ }^{1}$ Cunkun Chen, ${ }^{2} \mathrm{Li} \mathrm{Ma},{ }^{1}$ \\ Shaohua Li, ${ }^{1}$ Zhenming Che, ${ }^{1}$ and Hongbin Lin ${ }^{1}$ \\ ${ }^{1}$ Key Laboratory of Grain and Oil Processing and Food Safety of Sichuan Province, College of Food and Bioengineering, \\ Xihua University, Chengdu 610039, China \\ ${ }^{2}$ Key Laboratory of Physiological and Storage of Postharvest Agricultural Products of Agriculture Ministry, \\ National Engineering Technology Research Center for Preservation of Agricultural Products, Tianjin 300384, China
}

Correspondence should be addressed to Yage Xing; xingyage1@aliyun.com and Qinglian Xu; 775938414@qq.com

Received 8 June 2016; Revised 29 September 2016; Accepted 11 October 2016

Academic Editor: Agnieszka Kyzioł

Copyright (c) 2016 Yage Xing et al. This is an open access article distributed under the Creative Commons Attribution License, which permits unrestricted use, distribution, and reproduction in any medium, provided the original work is properly cited.

\begin{abstract}
Chitosan coating is beneficial to maintaining the storage quality and prolonging the shelf life of postharvest fruits and vegetables, which is always used as the carrier film for the antimicrobial agents. This review focuses on the preparation, property, mechanism, and application effectiveness on the fruits and vegetables of chitosan-based coating with antimicrobial agents. Chitosan, derived by deacetylation of chitin, is a modified and natural biopolymer as the coating material. In this article, the safety and biocompatible and antimicrobial properties of chitosan were introduced because these attributes are very important for its application. The methods to prepare the chitosan-based coating with antimicrobial agents, such as essential oils, acid, and nanoparticles, were developed by other researchers. Meanwhile, the application of chitosan-based coating is mainly due to its antimicrobial activity and other functional properties, which were investigated, introduced, and analyzed in this review. Furthermore, the surface and mechanical properties were also investigated by researchers and concluded in this article. Finally, the effects of chitosan-based coating on the storage quality, microbial safety, and shelf life of fruits and vegetables were introduced. Their results indicated that chitosan-based coating with different antimicrobial agents would probably have wide prospect in the preservation of fruits and vegetables in the future.
\end{abstract}

\section{Introduction}

Fresh fruits and vegetables with good quality are very interesting to costumers and have benefits for the health of human body due to their good flavor, being colorful, and the contents in nutrients, such as vitamins, minerals, and amino acids [1, 2]. However, one of the important challenges for the storage safety of fruits and vegetables is related to its high decay rate and short shelf life period. This is because of the fact that they could still undertake the metabolism ceaselessly as the living organisms during the storage period $[3,4]$. Moreover, the shrink and loss of luster of surfaces and the rot of fruits could be observed because of the high water transpiration, the loss of nutrients, and the infection of spoilage microorganism during storage [5]. In the latest few years, many technologies, such as edible coating with antimicrobial agents, low temperature, controlled atmosphere package, and so on, have been developed in order to maintain the quality and safety of fruits and vegetables, which could prolong its shelf life during the storage and market periods $[4,6,7]$. However, serious environmental problems could be created by using the conventional packaging materials. Furthermore, the risk of chronic diseases could increase in the human body if pulps with the exceeding residue of chemical agents are always consumed $[3,8]$.

The investigation for the safe alternatives is increasing for the storage of fruits and vegetables, such as the development and application of chitosan-based coating enriched with 
active agents $[2,5]$. Chitosan coating is one of the promising techniques because of its excellent properties including the property to form the thin film on the fruit's surface, the property to avoid the loss of moisture and aromas, the inhibition of the oxygen penetration to the plant tissue or microbial growth, and the safety for using on the food [914]. More importantly, the use of active component in the chitosan-based coating is one promising method to improve its antimicrobial and antibrowning activities for the storage of fruits and vegetables [1, 15-18]. Many kinds of antimicrobial agents, such as essential oils, acid compounds, and nanoparticles, have been used to load into the coating films of chitosan [17-20]. The chitosan-based coatings were developed by using essential oils as the antimicrobials including lemon oil, rosemary oil, lemongrass oil, carvacrol oil, cinnamon oil, and bergamot oil [1, 2, 18, 20-26]. The nanoparticles of silicon dioxide were also used as the antimicrobials in the chitosan coating [27, 28]. Furthermore, Cai et al. [29] have developed the chitosan-based coating using nisin as the antimicrobials.

The chitosan coating enriched with antimicrobials exhibited the excellent inhibition on the growth of bacteria, yeast, and molds [30-34]. Postma et al. [35] displayed that the combined application of chitosan and Lysobacter enzymogenes could express better control effects on the development of Pythium aphanidermatum in cucumber. Moreover, as indicated by Chen et al. [36], the antimicrobial activity of chitosan nanoparticles could be enhanced by adding the components of grafted eugenol and carvacrol. Sánchez-González et al. [37] also reported that the coating of chitosan with bergamot oil could exhibit a significant inhibition against Penicillium italicum. Ma et al. [38] demonstrated that the inactivating functions of chitosan coating with lauric arginate (LAE), cinnamon oil, and ethylenediaminetetraacetic acid (EDTA) on foodborne pathogens were observed, such as Escherichia coli, Listeria monocytogenes, and Salmonella enterica, inoculated on cantaloupes. Furthermore, the investigation of Khalifa et al. [39] showed that the addition of olive oil residues extracts into chitosan coating could lead to the increase of antifungal activities against the tested strains, such as Penicillium expansum and Rhizopus stolonifer.

The chitosan-based coating incorporated with antimicrobials could extend the shelf life and improve the storage quality of fruits and vegetables [18, 38-40]. Xing et al. [18] reported that the applications of chitosan coating with cinnamon oil as the antimicrobials could provide better effect on the quality and decay of sweet peppers. The results of Kaya et al. [40] indicated that the use of chitosan-acetic acid coating might be an effective technology to prolong the short shelf life of red kiwifruit berries. Ma et al. [38] also reported that the chitosan-based coating with LAE, cinnamon oil, and EDTA could improve the microbiological safety and keep the quality of cantaloupe. Moreover, the study of Khalifa et al. [39] demonstrated that the applicability of chitosan coating incorporated with olive oil residues extracts could improve the shelf life stability of apple and strawberry fruits. Furthermore, the chitosan coating with antimicrobial agents has been successfully used in many other kinds of fruits, such as grape, berry, pear, jujube, and vegetables, such as mushroom and fresh-cut lotus root $[2,12,17,19,20,27,41]$.
The effectiveness of chitosan-based coating with antimicrobial agents has been reported and reviewed by workers on its application for enhancing the quality, controlling the rot, and extending the storage life of fruits and vegetables. $\mathrm{Yu}$ and Ren [4] have introduced the preserving effect of chitosan-based coating on the storage of fruits and vegetables. As reported by Duan and Zhang [3], they reviewed the effect of chitosan-based coating on the preservation of fruit and vegetable. Elsabee and Abdou [19] concluded the investigation on the chitosan-based edible films and coatings. Kerch [42] has summarized the recent studies on the effect of chitosan-based coatings on the changes of nutritional quality of fruits and vegetables during postharvest storage. The mechanisms of action and the role of polyphenols and vitamin $C$ in prevention of age-related diseases have been also discussed. Moreover, Romanazzi and Feliziani [43] also reviewed the control postharvest decay of temperate fruit by chitosan treatment. However, until now, no detailed report has been observed to summarize the preparation method, the microstructure, function properties, and application effectiveness of chitosan-based coating with antimicrobial agents for the storage of fruits and vegetables.

Therefore, the one aim of this article was to highlight the potential of chitosan as the active biobased coating material for antimicrobial agents and to summarize its different preparation methods. Moreover, another aim was to review their antimicrobial activity, mechanism and functional properties, and its application in the storage of fruits and vegetables. It is expected to provide insights for researchers working on the postharvest preservation of agricultural products.

\section{Preparation of Chitosan-Based Coating Films Incorporated with Antimicrobial Agents}

\subsection{Origin, Structure, and Property of Chitosan}

2.1.1. Origin, Chemical Structure, and Dissolubility of Chitosan. Chitin as the deacetylated derivative sources of chitosan is the second most abundant polysaccharide found in nature after cellulose, which consists of $N$-acetylglucosamine residues joined by $\beta$-1,4-glycosidic links $[4,44]$. The compound of chitin could constitute $20-30 \%$ of crustacean shells like cockles, shrimps, crabs, and so on $[4,44,45]$. The degradation process of chitosan from chitin and acid-base equilibrium attributes of chitosan are shown in Figure 1. Deacetylation is achieved by exposing chitin to strong $\mathrm{NaOH}$ solutions or to the enzyme chitinase [44-48]. Chitosan as linear polysaccharide consists of $(1,4)$-linked 2-amino-deoxy-b-d-glucan with two free hydroxyl and one primary amino groups [44-49]. The positive charge of amino groups could make it available to react with many negatively charged surfaces of cell and other polymer materials [49]. The quality and functional properties of chitosan are determined by many factors including the degree of deacetylation, molecular weight, the sources, and extraction pathway [49]. The dissolubility is one of the important properties for its application. However, chitosan is insoluble in organic or water solvents. It is only soluble in any 

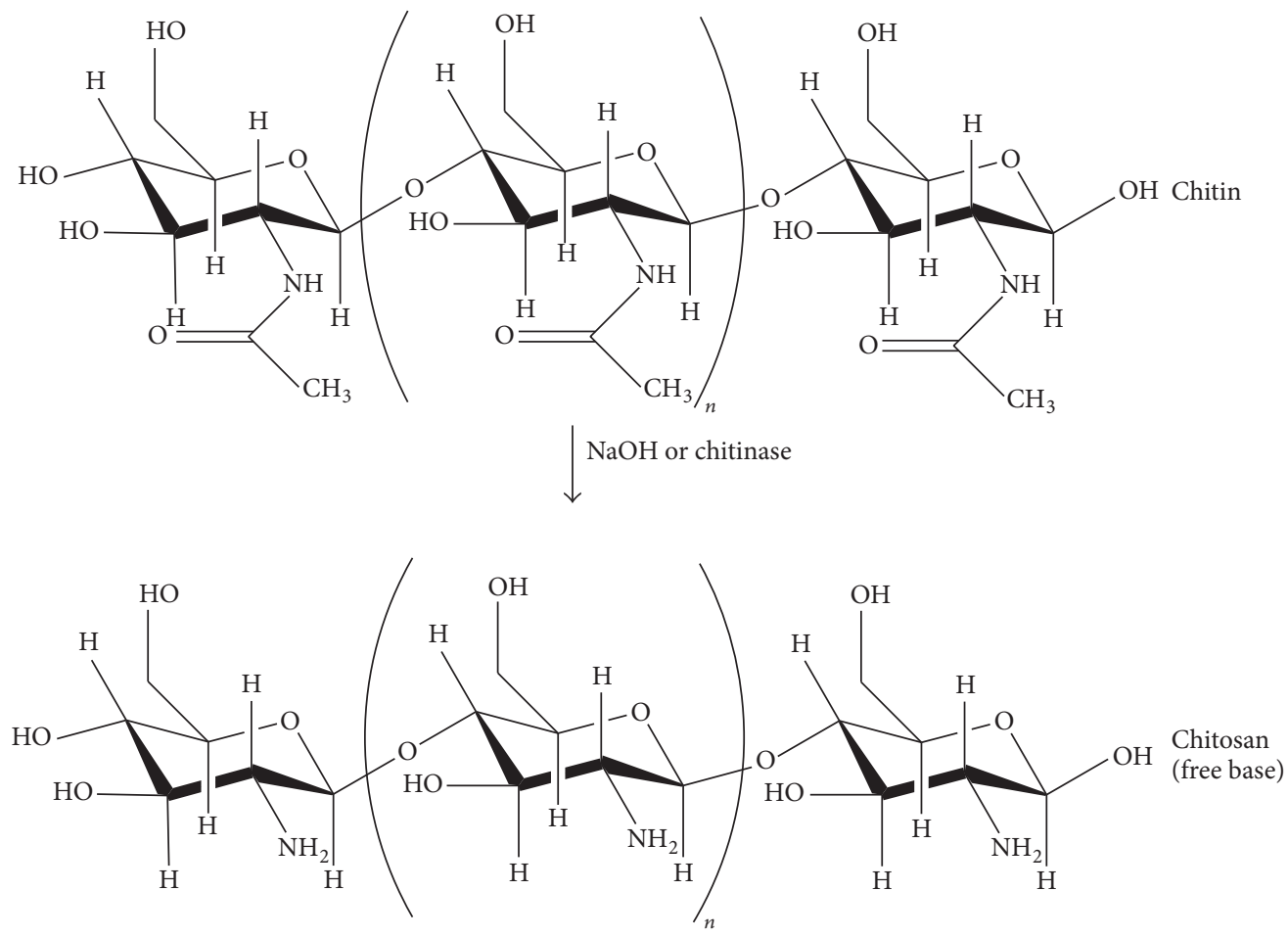

$\left.\right|^{ \pm \mathrm{H}^{+}}$

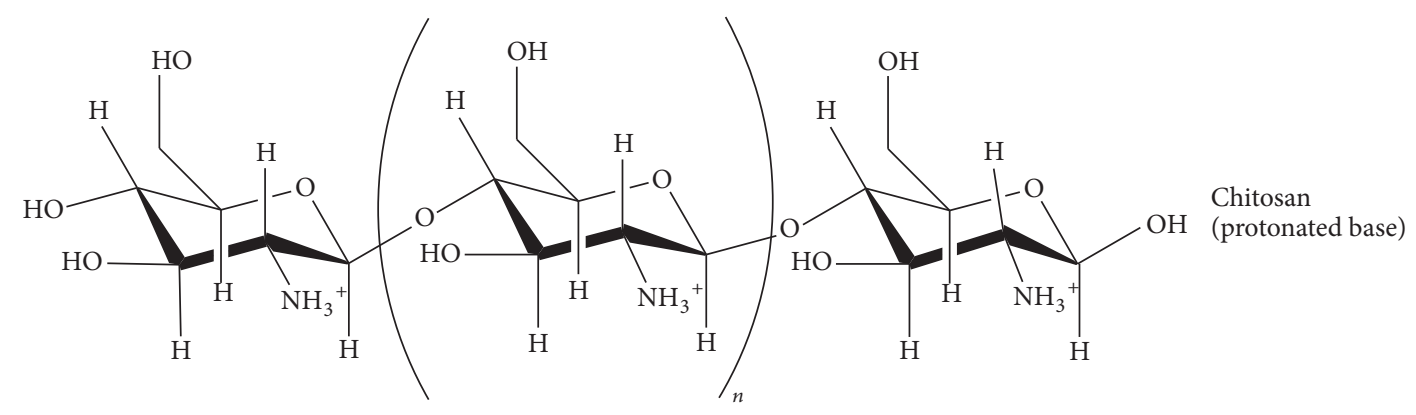

FIGURE 1: The deacetylation pathway of chitosan from chitin and the acid-base equilibrium attributes of chitosan $[44,47,48]$.

dilute aqueous acidic solution $(\mathrm{pH}<6.5)$ [46]. This might be due to the fact that these chitosan derivatives in the form of acetate, ascorbate, and malate are water-soluble.

2.1.2. Safety of Chitosan for the Application on Fruits and Vegetables. The safety of chitosan particles and solutions is very important for its application on the food industry and has been investigated by other researchers. Chitosan as a food additive had been approved in Japan and Korea since 1983 and 1995 , respectively $[50,51]$. Moreover, its biological safety has been indicated by feeding trials with domestic animals [52]. More importantly, as reported by Jeyanth Allwin et al. [53], chitosan has been considered as generally recognized as safe (GRAS) by the US FDA in 2005. Therefore, chitosan is considered as the biocompatible, nontoxic, and safety raw material for using on the fruits and vegetables [17, 45, 54].

2.1.3. Film-Forming Property and Biocompatibility of Chitosan. Chitosan coatings have been successfully used as the active packaging materials and the antimicrobial films for the quality of agricultural products, especially fruits and vegetables $[2,17,55]$. It should be due to its excellent filmforming property and biocompatibility $[2,17,55]$. As can be seen in the following list, the properties of film-forming and biocompatibility are the request characteristics for its application as the coating material, which could make it have the ability to be used as edible films, coatings, or packaging materials for the storage of fruits and vegetables $[1,18,56]$. 
As reported by Xing et al. [57], chitosan coating could form a thin film with micropores and improve the storability of perishable foods by decreasing the transpiration losses as well as modifying the internal atmosphere of package. Moreover, the biocompatibility of chitosan coating film could make it have the ability to be used as the carrier for antimicrobial agents. Chitosan has been also demonstrated to exhibit the distinctive property of biocompatibility for application, emulsification, and dye binding $[58,59]$. Thus, the application of chitosan with the excellent film-forming property and biocompatibility has attracted interest as the natural coating materials for maintaining the quality of fruits and vegetables $[2,17,41]$.

Potential Effectiveness and Requirement of Chitosan-Based Coating on the Storage Quality of Fruits and Vegetables [42, 60]. Potential effectiveness of chitosan-based coating on fruits and vegetables includes

(i) modified respiration rate;

(ii) keeping firmness and reducing weight loss;

(iii) controlling decay and rot;

(iv) delaying senescence and ripening;

(v) keeping sensory quality;

(vi) being a carrier for active compounds;

(vii) controlling nutrients loss;

(viii) maintaining aroma components.

Requirement of chitosan-based coating for using on fruits and vegetables comprise

(i) owning the space as the carrier for active substance;

(ii) being an excellent barrier of gas and water vapor;

(iii) excellent mechanical properties;

(iv) high stability under high relative humidity;

(v) good antimicrobial activity;

(vi) negligible taste and color;

(vii) excellent adhesion property on the fruits surface;

(viii) high physicochemical stability and low cost.

2.1.4. Antimicrobial Activity of Chitosan. Chitosan is always used as a potential food preservative which might be due to its antimicrobial activity against a range of foodborne bacteria, yeast, and fungi. On the other hand, the potential antimicrobial activities as well as others were shown in the previous list, which are mainly important requirements for its application on fruits and vegetables [1, 61]. The stronger antimicrobial activity was observed for the chitosan with a higher deacetylation degree [62]. Moreover, chitosan with low molecular weight might express better antimicrobial activity than that with high molecular weight [63]. The antimicrobial activity of chitosan might be increased by low $\mathrm{pH}$ values due to its protonation in the acidic $\mathrm{pH}$ interval and higher solubility in the acid microenvironment [64]. On the other hand, temperature and the surrounding matrix could affect the antimicrobial activity of chitosan coating [62].

For the antimicrobial activity of chitosan, it is reported that yeasts and molds exhibited the higher sensitivity compared to bacteria [62]. The investigation of Qi et al. [65] displayed that the chitosan nanoparticles could control the growth of bacteria such as E. coli, Salmonella choleraesuis, Salmonella typhimurium, and Staphylococcus aureus. Ganan et al. [66] also reported that, among a number of tested pathogens, Campylobacter spp. was the most susceptible one to inactivation by chitosan. Lou et al. [67] showed that the solution of chitosan had strong antibacterial activity against Burkholderia seminalis. The high antimicrobial activity of chitosan was also observed by Han et al. [68]. Moreover, Ristić et al. [69] indicated that Lactobacillus inhibition of chitosan nanoparticles is reflected in low minimal inhibitory concentration. As reported by Madureira et al. [70], chitosan nanoparticles could affect the cellular structure of bacteria and reinforce their antimicrobial activity. Furthermore, Wang et al. [71] reported that the growth of fungi could strongly be inhibited by the treatment of chitosan. Kaya et al. [72] observed that chitosan with the low molecular weight scorpion exhibited the specific antimicrobial activity to bacterial species in general. Moreover, Li et al. [64] indicated that the $\mathrm{pH}$ value for the highest antibacterial activity of chitosan was 6.0. The antibacterial activity of chitosan solution ( $\mathrm{pH}$ 6.0) against E. coli and $S$. aureus could be enhanced with increasing its deacetylation degree. As reported by Mohammadi et al. [73], the antibacterial activity of chitosan nanoparticles was significantly enhanced in comparison to that of chitosan microparticles. Sayari et al. [74] suggested that chitosan exhibited the inhibitory activity against the tested strains of bacteria and fungi. Goy et al. [75] also indicated that the antibacterial effectiveness of chitosan was significantly affected by its applied concentration.

2.2. Preparation of Chitosan-Based Coating Films with Antimicrobial Agents. Many kinds of chitosan-based coating with antimicrobial agents have been developed by researchers, as shown in Figure 2, such as chitosan-based coating with essential oils and acid compounds and nanoparticles [1720]. However, one important problem for preparing these chitosan-based coatings is the uniform dispersion of antimicrobial agents in the chitosan solution system. Therefore, the technologies were reported by many researchers in order to resolve this problem and develop these complex coatings with high antimicrobial activity for their application.

\subsubsection{Preparation of Chitosan-Based Coating with Essential} Oils. In the industry of fruits and vegetables, edible biobased coating could offer many advantages because of its carrier property for antimicrobial agents, such as essential oil, against pathogenic microorganisms [17-20,76]. Therefore, the chitosan-oil coating has been developed by incorporating it with different essential oils.

The chitosan-based coating with lemon essential oil as the antimicrobials was prepared by Perdones et al. [20]. Firstly, chitosan was dispersed in an aqueous solution with 


\begin{tabular}{|c|c|c|}
\hline Carrier coating & Different ant & bial agents \\
\hline $\begin{array}{l}\text { Based materials: } \\
\text { (i) Chitosan } \\
\text { Function: } \\
\text { (i) Film-forming } \\
\text { (ii) Antimicrobial } \\
\text { activity } \\
\text { (iii) Safety } \\
\text { (iv) Biocompatibility } \\
\text { (v) Micropores } \\
\text { Structure: }\end{array}$ & $\begin{array}{l}\text { Essential oils: } \\
\text { (i) Lemon oil [20] } \\
\text { (ii) Rosemary oil [21, 77] } \\
\text { (iii) Sun flower oil [22] } \\
\text { (iv) Lemongrass oil [23] } \\
\text { (v) Carvacrol oil [24] } \\
\text { (vi) Bergamot oil [26] } \\
\text { (vii) Mentha piperita L. oil Mentha × } \\
\quad \text { villosa Huds oil [78] } \\
\text { (viii) Eucalyptus globulus oil [79] } \\
\text { (ix) Cinnamon oil [1,2, 18, 25, 37, 80] } \\
\text { Nanomaterials: } \\
\text { (i) Nanosilicon dioxide [27, 28, 89] } \\
\text { (ii) Nanosilica hybrid [88] }\end{array}$ & $\begin{array}{l}\text { Acid compounds: } \\
\text { (i) Acetic acid } \\
\quad[17,38,80,40,76,85,86] \\
\text { (ii) Ascorbic acid [17] } \\
\text { (iii) Citric acid [17] } \\
\text { (iv) Lactic acid [85] } \\
\text { (v) Glacial acetic acid [82] } \\
\text { Other materials: } \\
\text { (i) Nisin [29] } \\
\text { (ii) Beeswax [90] } \\
\text { (iii) Maillard reaction products [91] } \\
\text { (iv) Green tea leaves extract [92] } \\
\text { (v) A. vera fraction [93] } \\
\text { (vi) Olive leaf and pomace extracts } \\
\text { [94] }\end{array}$ \\
\hline
\end{tabular}

FIGURE 2: The preparation of chitosan-silver antimicrobial nanocomposites [47].

glacial acetic acid. Then, lemon essential oil was added and emulsified after chitosan dissolved. This obtained emulsion was submitted to a second homogenization at $165 \mathrm{MPa}$ in a single pass by using microfluidization in order to obtain the composited chitosan coating.

The chitosan coating incorporated with rosemary essential oil and nanoclay was developed by Abdollahi et al. [21]. Chitosan powder was firstly dissolved in aqueous acetic acid solution at $90^{\circ} \mathrm{C}$ by stirring for $20 \mathrm{~min}$ and cooled to the room temperature. The certain amounts of clay were dispersed in aqueous solution of acetic acid by stirring for $24 \mathrm{~h}$. Then, chitosan solution was added into the obtained clay solutions and stirred for another $4 \mathrm{~h}$. Moreover, Tween 80 as an emulsifier was added to the mixture and stirred at $40^{\circ} \mathrm{C}$ for $30 \mathrm{~min}$. Finally, the appropriate amounts of rosemary oil were added to the solution. The chitosan-oil solution was finished after being homogenized and degassed under vacuum for 5 min.

Xiao et al. [77] reported the preparation method of chitosan-based coating with rosemary extracts. Firstly, the chitosan was dispersed in an aqueous solution of glacial acetic acid at $4^{\circ} \mathrm{C}$. Then, the compounds of glycerol and Tween 80 were added into the mixture solution. After being homogenized for $10 \mathrm{~min}$, the $\mathrm{pH}$ value of the complex solution was adjusted to 5.6 by using $\mathrm{NaOH}$. The solution was strained through layers of cheesecloth and degassed under vacuum at room temperature. Finally, the rosemary extract as the antimicrobial agent was added into the obtained chitosan solution.

The investigation of Valenzuela et al. [22] suggested that the blends and coating films of quinoa protein extracts (Q), chitosan $(\mathrm{CH})$, and sun flower oil blends (SO) were prepared. Firstly, the aqueous quinoa protein extracts were prepared. The quinoa flour was suspended in distilled water and its $\mathrm{pH}$ was adjusted to $\mathrm{pH} 8$ and $\mathrm{pH} 12$, respectively. The obtained suspensions were stirred and centrifuged. The supernatants of quinoa flour suspensions at $\mathrm{pH} 8$ and $\mathrm{pH}$ 12 were named as Q-8 and Q-12, respectively. Secondly, the chitosan solution was prepared. Solutions of chitosan in citric acid with different concentrations were prepared, sonicated, and left overnight. The blends were prepared by mixing solutions of Q-8 or Q-12 and $\mathrm{CH}$ with different Q/CH ratios. Finally, the Q/CH/SO was prepared. The optimal Q/CH ratio was blended with SO at different concentrations and Tween 80. The blends were prepared by mixing Q, SO, and Tween 80 and were homogenized. Then, chitosan was incorporated into the blend by mixing and its $\mathrm{pH}$ value was adjusted to 3.0.

Ali et al. [23] reported the method to prepare the chitosan and lemongrass oil coating. Chitosan solutions at $\mathrm{pH}$ 5.65.9 were prepared using low molecular weight chitosan. After that, lemongrass essential oil and Tween 80 were added to chitosan solutions. Moreover, to ensure incorporation of lemongrass essential oil in chitosan, the solutions were mixed using a homogenizer.

Severino et al. [24] also developed the chitosan coating with essential oils. The modified chitosan was dissolved in acetic acid solution by stirring for $24 \mathrm{~h}$. Then, carvacrol oil nanoemulsion was added into the obtained chitosan solution and mixed vigorously to obtain the chitosan-oil coating.

Sánchez-González et al. [26] reported the technology to prepare the chitosan coating with bergamot essential oil. Chitosan was dispersed in an aqueous solution of glacial acetic acid at $40^{\circ} \mathrm{C}$ for $12 \mathrm{~h}$. Then, bergamot essential oil was added and emulsified. The chitosan-oil coating was obtained after being degassed at room temperature using a vacuum pump.

The chitosan coatings with Mentha piperita L. essential oils (MPEO) and Mentha $\times$ villosa Huds essential oils (MVEO) were prepared by Guerra et al. [78]. Firstly, chitosan was initially diluted in acetic acid with stirring for $6 \mathrm{~h}$. Different amounts of MPEO or MVEO were incorporated into this chitosan solution and stirring was for another $18 \mathrm{~h}$. Finally, 
glycerol was added into the coating-forming solution. The similar procedure was also reported by dos Santos et al. [12] to develop the chitosan coating with Origanum vulgare L. essential oil for fruit storage.

Hafsa et al. [79] have developed the chitosan-based coating films. Coating solution was prepared by dissolving chitosan in a solution of glacial acetic acid with stirring at $50^{\circ} \mathrm{C}$. The resultant chitosan solution was filtered and followed by vacuum filtration. Glycerol was added into chitosan in the solution and mixed for $30 \mathrm{~min}$. Then, Tween 80 was also added into the essential oil of Eucalyptus globulus and stirring was for $15 \mathrm{~min}$. Finally, the emulsified essential oil was added into the obtained chitosan solution.

The chitosan-based coating enriched with cinnamon essential oil was prepared by Xing et al. $[1,2,18]$. The chitosan solution containing acetic acid and glycerol plasticizer was stirred for $1 \mathrm{~h}$. Then, the compounds of cinnamon oil and Tween 80 were added into the chitosan solution and then stirred by a magnetic stirrer for $30 \mathrm{~min}$. The obtained solution was homogenized under aseptic conditions.

Mohammadi et al. [25] reported that the solution of Cinnamomum zeylanicum essential oil- (CEO-) chitosan nanoparticles was prepared by an ionic gelation. Chitosan was firstly dissolved in solution of acetic acid and Tween 80 was added. After stirring, CEO was dropped into the chitosan solution under the stirring condition. The agitation was conducted for $30 \mathrm{~min}$ in order to obtain an oil in-water emulsion. The solution of CEO-loaded chitosan nanoparticles could be obtained by the drop-wise addition of tripolyphosphate solution into the oil in-water emulsion under stirring.

Ma et al. [38, 80] have reported the technology to prepare the mixture coating solution of chitosan, acetic acid, LAE, EDTA, and cinnamon oil. The based coating solution was prepared by dissolving chitosan in an aqueous solution with acetic acid and stirred overnight. After removing the impurities, the compounds of LAE, EDTA, and cinnamon oil were added into the chitosan solution by mixing until it was homogeneous.

\subsubsection{Preparation of Chitosan-Based Coating with Acid Com-} pounds. The compounds of organic acids are noncorrosive in nature, biodegradable, and safe for the storage of fruits and vegetables, which could be used to prevent enzymatic browning and control the decay of pulps, alone or in combination with antimicrobial agent [81-84].

Vásconez et al. [76] reported the method to prepare the chitosan-acetic acid solution. The coatings could be obtained by the addition of chitosan-acetic acid solution to gelatinized tapioca starch/glycerol or tapioca starch/glycerol/potassium sorbate mixtures. These obtained mixtures were homogenized using a dispersion device. Then, the air in the solutions was also removed by using vacuum. Finally, all the solutions prepared were adjusted to $\mathrm{pH} 4.0$ with acetic acid.

Xing et al. [17] have developed the coating solution by dissolving chitosan in distilled water containing acetic acid. The obtained solution was stirred for $1 \mathrm{~h}$. Then, ascorbic acid
(2\%) and citric acid (1\%) were added and stirred for another $30 \mathrm{~min}$. This chitosan-based coating solution could be used after standing for $1 \mathrm{~h}$.

The chitosan coating with glacial acetic acid and olive oil was developed by Ochoa-Velasco and Guerrero-Beltrán [82]. Chitosan solution was prepared by placing glacial acetic acid and olive oil into a volumetric flask and made up to volume with distilled water. Then, the solution was poured into a beaker, warmed, and blended using a homogenizer. Finally, one gram of chitosan with medium molecular weight and $85 \%$ deacetylated degree was added slowly while stirring until completely dispersed.

Kaya et al. [40] reported the method to prepare the chitosan-acetic acid coating solution. Firstly, chitosan was dissolved in acetic acid solution at pH 2.0-2.3. The dissolved process was conducted by a continuous stirring for 2 days at $40^{\circ} \mathrm{C}$. Then, the coating solution was degassed under vacuum and filtered in order to remove the undissolved particles.

The investigation of Jovanović et al. [85] has also introduced the technology to develop the coatings by dissolving chitosan with medium molecular weight in the acetic acid solution or lactic acid solution and stirring for $24 \mathrm{~h}$.

The investigation of Flores et al. [86] reported the method to prepare the coating solution by dissolving chitosan powder in a hydroalcoholic acid solution under stirring for $6 \mathrm{~h}$ at room temperature. After removing impurities by vacuum filtration, glycerol was added into the chitosan solution and stirred for another $30 \mathrm{~min}$.

\subsubsection{Preparation of Chitosan-Based Coating with Nanoma-} terials. Chitosan-based coating film with different nanoparticles has been developed in recent years. The differences between normal-sized substances and nanosized substances indicate the effectiveness of small size, surface, and macroscopic quanta size [84-87]. The developed works have been conducted by using nanoparticles as antimicrobials.

Shi et al. [88] reported the technology to prepare the chitosan/nanosilica hybrid coating film. Chitosan coating solution was dispersed in the glacial acetic acid solution by stirring for $48 \mathrm{~h}$. Further, the certain amount of tetraorthosilicate was added to the above solution and stirred with a magnetic stirrer. Then, the equal mixture of ethanol and water was added to this solution and stirred for $20 \mathrm{~h}$. The $\mathrm{pH}$ value of the obtained solution was adjusted to 5.6. The chitosan/nanosilica hybrid coating was obtained after being vacuumed for $2 \mathrm{~h}$.

Yu et al. [27] have reported the preparation of chitosanbased coating with nanosilicon dioxide. First, the mixed solution of chitosan, nanosilicon dioxide, and deionized water was dispersed for $15 \mathrm{~min}$ by ultrasonication under $300 \mathrm{~W}$ at $60^{\circ} \mathrm{C}$. Second, sucrose ester of fatty acid was added into the above solution and dispersed for $5 \mathrm{~min}$. The chitosan coating with nanosilicon dioxide could be obtained after adding the glycerine and dispersed.

Song et al. [89] have developed the chitosan/nanosilica coating. Chitosan was dissolved in a solution of glacial acetic acid and then stirred for $8 \mathrm{~h}$. Silica solution was prepared at a molar ratio of tetraorthosilicate: deionized water : ethanol 
$(1: 4: 1)$. After stirring at $200 \mathrm{rpm}$ for $2 \mathrm{~h}$, the solution was kept for $30 \mathrm{~min}$ prior to mixing with the chitosan solution. The $\mathrm{pH}$ of obtained solution was adjusted to 5.6. Then, the silica solution was added to the chitosan solution and homogenized by ultrasonication for $30 \mathrm{~min}$ at $60^{\circ} \mathrm{C}$. Finally, sucrose ester of fatty acid was added and stirred.

The chitosan solution with nanosilicon dioxide was prepared by Sun et al. [28]. Chitosan was dissolved in acetic acid solution at $50^{\circ} \mathrm{C}$ under stirring. The sodium silicate solution was added into the hydrochloric acid solution for adjusting the $\mathrm{pH}$ value to 4-5, and acidic silicon sol was obtained. With sufficient mixing, acidic silicon sol and sodium dodecyl benzene sulfonic saturated solution were dropwise added in the chitosan solution. The synthesis solution of nano-SiOx and chitosan was prepared after glycerol was added into the solution under stirring at $50^{\circ} \mathrm{C}$.

\subsubsection{Preparation of Chitosan-Based Coating with Other} Materials. The preparation technologies of chitosan-based coating with other antimicrobial agents, such as nisin, were conducted. These investigations could be enriched with the kinds of chitosan-based coating with antimicrobial agents and provide the methods for other researchers.

Cai et al. [29] introduced the method to develop the chitosan/nisin coating. In order to prepare the chitosan/nisin complexes, chitosan was dissolved in an acetate buffer at $\mathrm{pH}$ 4.8. The concentration of the chitosan-acetate solution was adjusted to $1 \%(\mathrm{w} / \mathrm{v})$. Nisin was dissolved in an acetate buffer and the concentration of nisin was also adjusted to $0.01 \%$ $(\mathrm{w} / \mathrm{v})$. Then, the chitosan solution was added to the same volume of nisin solution. The resulting solution was carefully stirred for $3 \mathrm{~h}$ and then stored for at least 1 day at room temperature.

Velickova et al. [90] have developed the chitosan-beeswax coating. Chitosan was dissolved in acetic acid with stirring. The complete dissolution of chitosan, glycerol, and Tween 80 was added and stirred for another $30 \mathrm{~min}$. Then, after being centrifuged, the cross-linking of the chitosan coating was carried out with sodium tripolyphosphate. For beeswax coatings, wax solution was prepared firstly by melting beeswax in ethanol heated to $70^{\circ} \mathrm{C}$ and emulsified with Tween 80 . The composite coating could be obtained by mixing the solutions of chitosan and wax.

Li et al. [91] have prepared the chitosan-maltose Maillard reaction products (MRP) coating. One gram of chitosan was dissolved in solution with $100 \mathrm{~mL}$ of acetic acid (1\%) in which $1.0 \%$ of maltose was added. The $\mathrm{pH}$ value of each solution was adjusted to 6.0. Then, the above obtained mixture of chitosan, acetic acid, and maltose was heated in a $100^{\circ} \mathrm{C}$ water bath for $6 \mathrm{~h}$ and withdrawn at given time intervals. The coating sample could be completed after being cooled in iced water.

The chitosan-based coating incorporated with green tea extract was prepared by Sabaghi et al. [92]. Firstly, the chitosan powder was dissolved in an aqueous solution of glacial acetic acid under stirred conditions at $60^{\circ} \mathrm{C}$ and then glycerol was added to the chitosan solution. Chitosan solution was stirred for $15 \mathrm{~min}$. Then, the green tea leaves extract was filtered and was added to the chitosan solution.
Vieira et al. [93] reported that the coating solution was prepared by dissolving chitosan into the solution of lactic acid by stirring for $10 \mathrm{~h}$ at $20^{\circ} \mathrm{C}$. Then, Tween 80 and glycerol were added in the chitosan solution. Finally, the fraction of Aloe vera (liquid or pulp) as antioxidant and antimicrobial agent was added and stirring was for $3 \mathrm{~h}$ at room temperature in order to obtain the complete dissolution.

Khalifa et al. [94] developed the chitosan solutions incorporated with ethanolic olive leaf extracts and olive pomace extracts. Chitosan was dispersed in an aqueous solution of glacial acetic acid at $40^{\circ} \mathrm{C}$. Then, the solution was heated and agitated for $12 \mathrm{~h}$. After adjusting the $\mathrm{pH}$ to 5.6, glycerol was added and stirred overnight. The olive oil wastes extracts were added and mixed for achieving the complete dispersion.

\section{Antimicrobial Activity of Chitosan-Based Coating with Antimicrobial Agents}

The quality and shelf life of postharvest fruits and vegetables could be significantly reduced during the storage time because they are easily vulnerable to all kinds of spoilage microorganisms. Chitosan-based coating with antimicrobial agents could form the thin film on the surface of fruits and vegetables and inhibit the growth of indigenous or inoculated bacteria, yeast, and molds [30-34]. As indicated in Figure 3, the antibacterial and antifungal activity of chitosan-based coating could be affected by many factors, like the properties of chitosan, the concentration of antimicrobial agents, the type of microorganism, and so on. As indicated by Postma et al. [35], the application of chitosan with L. enzymogenes could reduce the number of diseased plants for cucumber by 50-100\%. L. enzymogenes combined with chitosan expressed the strong biocontrol effects on P. aphanidermatum in hydroponically grown cucumber. Moreover, Carlson et al. [95] revealed that the chitosan coating could reduce the viable cell populations in biofilm for Staphylococcus epidermidis, S. aureus, and Candida albicans. Cai et al. [29] also indicated that the coating of chitosan/nisin exhibited the higher antimicrobial activities against the tested strains of fungi and bacteria. The investigation of Sánchez-González et al. [37] also displayed that the antifungal activity of chitosan with bergamot oil on the growth of $P$. italicum was dependent on the oil concentration. Gómez-Estaca et al. [96] demonstrated that chitosan-gelatin coating films incorporated with clove oil showed higher inhibitory effect than that with rosemary and lavender oils. Furthermore, according to the results of Xing et al. [1], the antifungal activity of chitosan-oil coating against Penicillium citrinum could be enhanced by increasing the concentration of cinnamon oil. dos Santos et al. [12] suggested that the application of chitosan combined with Origanum vulgare L. essential oil could inhibit the mycelial growth of Aspergillus niger and $R$. stolonifer. The investigation of Bedel et al. [97] also showed that the combination of chitosan with poly(ethylene glycol) or sodium bicarbonate exhibited high antibacterial activity on E. coli and S. aureus. Chitosan coatings enriched with other antimicrobials expressed effective antimicrobial activity [42, 98, 99]. Severino et al. [24] reported that the antibacterial function of chitosan-based 


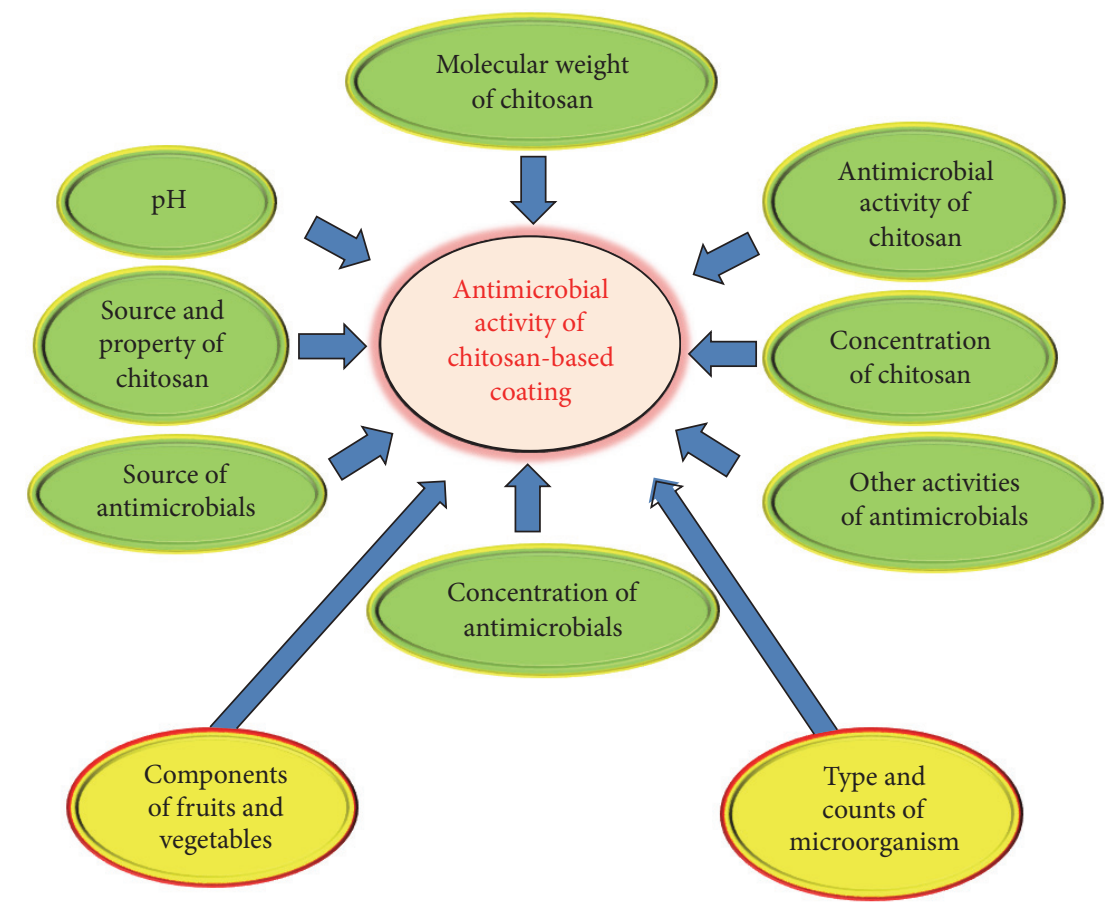

FIGURE 3: Factors that affected the antimicrobial activity of chitosan-based coating [176].

coatings enriched with carvacrol nanoemulsion oil was also observed. As reported by Ma et al. [38], the chitosan coating with LAE, cinnamon oil, and EDTA could significantly reduce the counts of bacteria, molds, and yeasts. Jovanović et al. [85] displayed that the chitosan coating films exhibited the strong antimicrobial activity against Listeria monocytogenes on black radish. Moreover, Khalifa et al. [39] showed that the activity of chitosan coating with the extracts of olive oil residues against $P$. expansum was higher than that against $R$. stolonifer in in vitro and in vivo test.

The effectiveness in reducing microbial growth of these complex coatings might be mainly because of the antimicrobial property of chitosan materials and the active substances in the based carrier, which could evaporate and diffuse to the medium in the package $[1,2,18,41]$. The main mechanism for antimicrobial activity of chitosan should be due to the interaction between the positively charged amino $\left(-\mathrm{NH}_{3}\right)$ groups of chitosan and the negatively charged carboxylate (-COO-) groups on the surface of bacterial cell membranes $[100,101]$. As indicated in Figure 4, such electrochemical binding could lead to the weakening and disruption of cell membranes. This mechanism was supported by the analysis of scanning electron microscopy (SEM) and atomic force microscopy (AFM) [65, 102]. Wang et al. [71] reported that the plasma membrane of Sclerotinia sclerotiorum mycelia treated by chitosan was observed to be damaged. The higher lipid peroxidation and protein leakage were found in chitosan-treated mycelia. Lou et al. [67] showed that the antibacterial activity of chitosan might be due to the membrane disruption and abnormal osmotic pressure from the assays of out membrane permeability and the observation of transmission electron microscopy (TEM). Moreover, Ristić et al. [69] indicated that chitosan nanoparticles interact with the membrane of Lactobacillus cells, causing the perturbation of the membrane wall and leading to the death of the cells. As reported by Madureira et al. [70], it was possible to obtain that the chitosan nanoparticles could affect the cellular structure of bacteria. Li et al. [64] indicated that the antibacterial activity of chitosan with high molecule weight might be due to the amino protonation and subsequently cationic formation. Its ultralong molecular chain was propitious to coat and binds the cells of $E$. coli and $S$. aureus, which were restrained and then decomposed gradually by chitosan. Furthermore, according to the investigation of Mohammadi et al. [73], the observation of AFM on the cultures of selected bacteria species treated by chitosan nanoparticles revealed the marked structural changes in the cell wall of bacteria. The antimicrobial mechanism is related to the presence of charged groups in the polymer and their ionic interactions with the constituents of bacteria wall [75, 103, 104]. The results of Raafat et al. [105] also demonstrated that the binding of chitosan to teichoic acids accompanied by the extraction of membrane lipids could induce the death of bacteria. Cell death might result from a sequence of the cited molecular events occurring simultaneously [105]. The molecular basis for the apparent differences in susceptibilities among different bacteria and fungi to chitosan was analyzed by other researchers [44]. Binding of bacterial trace metals by chitosan could inhibit the production of bacterial toxins and the microbial growth $[106,107]$. Besides, the interaction of diffused hydrolysis products with microbial DNA could induce the inhibition of the mRNA and protein synthesis $[107,108]$. Differences in the composition, structure, thickness, and electrochemistry of cell membrane could also affect 


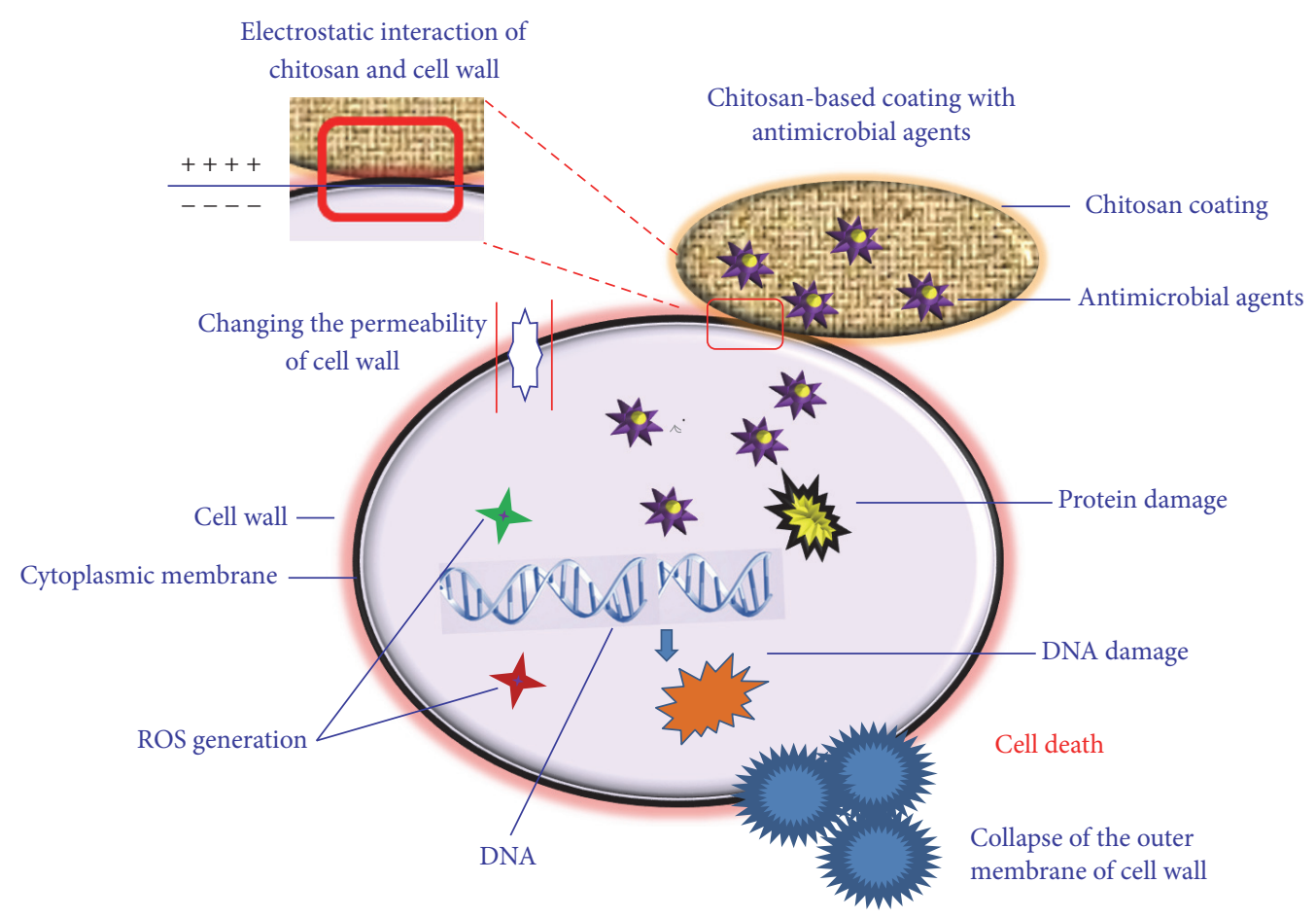

FIgURE 4: Antimicrobial mechanism of chitosan-based coating with antimicrobial agents $[175,176]$.

the sensitivities of different microorganisms to the inactivation of chitosan.

The high antimicrobial activity of chitosan-based coating should be due to the activity of active compounds in the barrier, such as essential oils, acids, and nanoparticles [1, 41, 84]. For the chitosan-oil coating, the source and functional groups, as well as composition of essential oils, could significantly influence their antimicrobial activity $[1,109]$. As can be seen in Figure 5(a), the sparse hyphae mycelium of P. citrinum with irregular shapes is observed around the inhibition zone of cinnamon oil. The normal growth or germination of spores was not observed, which might be inhibited by cinnamon oil. However, a normal morphology with linearly shaped hyphae and formed spores can be seen from the normal cell of $P$. citrinum on PDA in Figure 5(b). The antimicrobial properties of chitosan-based coating films enriched with essential oils should be due to the major compounds in oil $[1,78]$. For example, cinnamaldehyde and trans-cinnamaldehyde are the main active components of cinnamon oil [110]. The main compounds responsible for the antimicrobial activity of tea tree oil are 1,8-cineole and terpinen-4-ol [37].

\section{Gas Modification, Induction Defense, and Physical Properties of Chitosan-Based Coating with Antimicrobial Agents}

4.1. Gas Modification Property of Chitosan-Based Coating with Antimicrobial Agents. Aerobic respiration is an important activity for the quality and shelf life of fruits and vegetables during the storage period. However, the higher respiration rate of these pulps in the packaging system could be related to the higher nutrients consumed as respiration substrate and the decline in their nutritious value. The chitosan-based coating could properly restrain their respiration rate, which is beneficial to reserve the water, inhibit the loss of weight, maintain the firmness, and prolong the shelf life for fruits and vegetables [20, 111, 112]. Moreover, chitosan-based coating with semipermeable property on the surface of fruits could retard the fruits ripening by modifying the concentrations of $\mathrm{CO}_{2}, \mathrm{O}_{2}$, and ethylene in the packages [17], which could also modify the internal atmosphere in the fruit tissue. This permeability might be due to the micropores existing in the surface of chitosan-based coating film, as shown in Figure 6. This effectiveness on the pulps was consistent with the results reported by Xing et al. [2, 17] and Sun et al. [113]. The micropores in the coating film could also control and modify the release of antimicrobial agents such as essential oils to the package and in the fruits tissue, as shown in Figure 7, which could provide the higher antimicrobial activity and induce the defense activity for the storage of pulps.

Permeability is one important property of chitosan-based coating that could control the diffusion of antimicrobial agents, such as cinnamon oil, through a carrier film to the packages, with a driving force due to the different concentrations of substances between the two sides of coating film [114]. Oxygen might be the critical factor to cause oxidation and further induce the several unwanted changes of fruits and vegetables, such as the deterioration of odor, flavor, and nutrients. On the other hand, carbon dioxide could form in the packages of fruits and vegetables due to respiration reactions and deterioration [115]. Chitosan-based coating as the barrier of gases might provide the help needed for keeping 


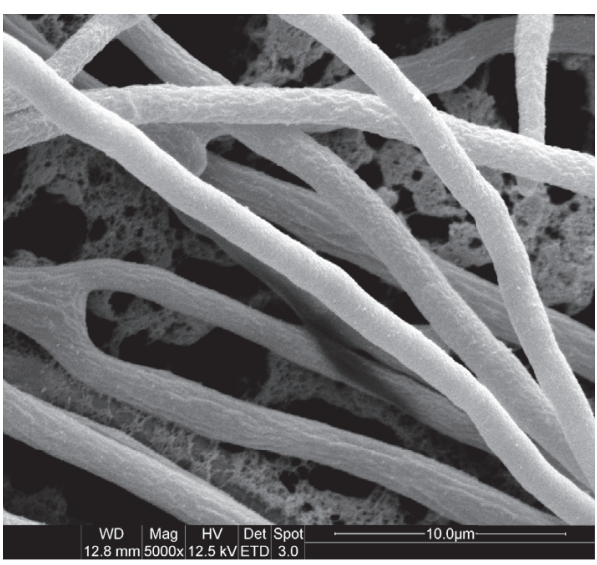

(a)

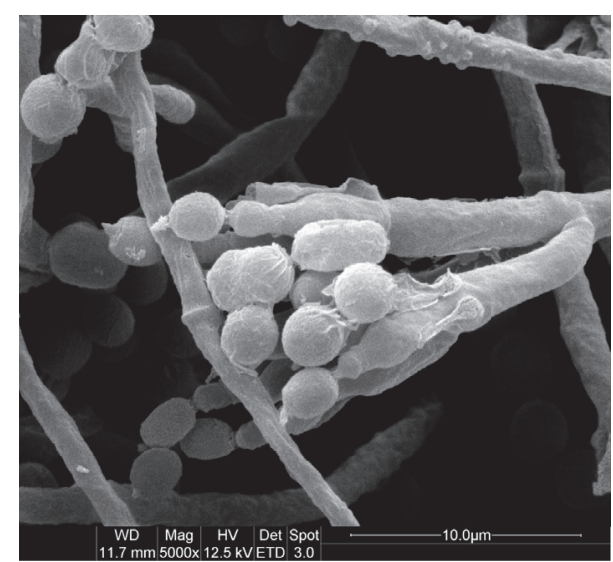

(b)

FIGURE 5: SEM images of the cell of P. citrinum on the edge of inhibition zone of cinnamon oil (a) and normal cell for P. citrinum (b) [57].

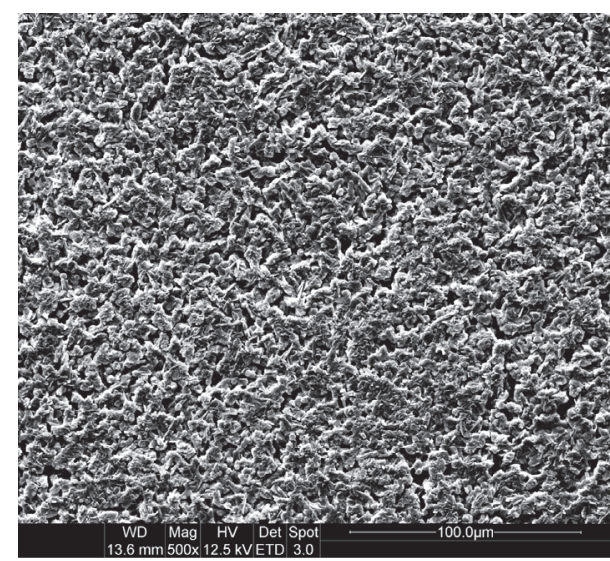

(a)

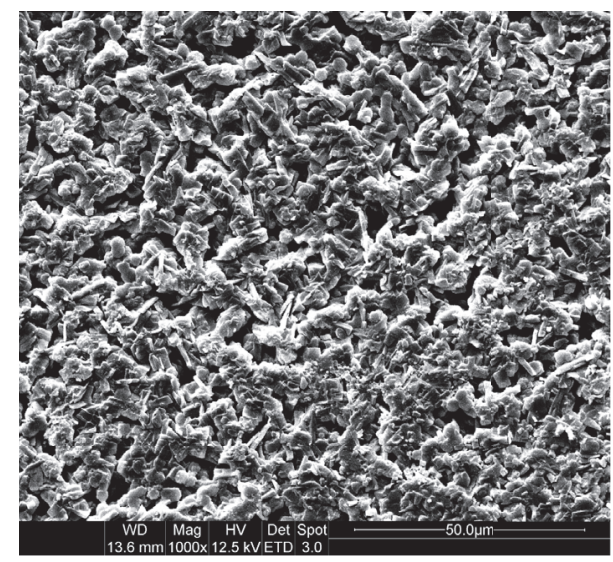

(b)

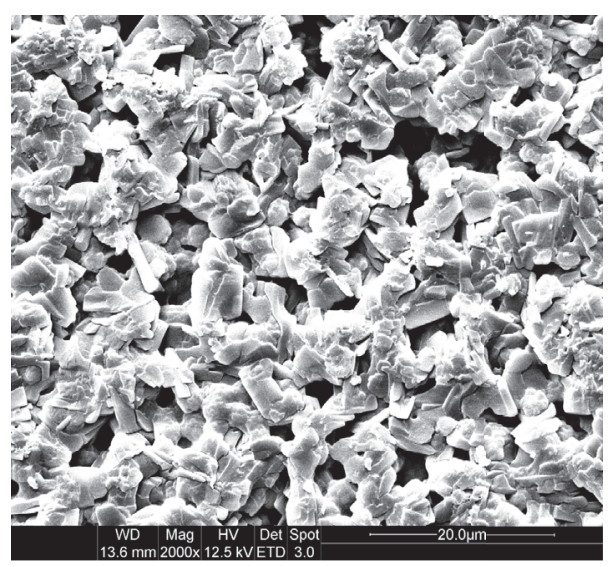

(c)

FIGURE 6: Morphological observation of chitosan-based coating by SEM ((a) ×500; (b) $\times 1000$; (c) $\times 2000)$ [57].

the quality and extending the shelf life of agricultural products [2, 94]. Gas permeability of chitosan-based coating depends on several key factors, such as the integrity of thin coating film, the number of micropores, the thickness of chitosan coating, and the interaction between the coating polymer and the additives $[116,117]$. The permeability of chitosan-based coating film on the surface of products could not be effectively adjusted if the coating is too thin. However, the dioxide carbonate could also be accumulated if the film is much thicker. This is because of the fact that, as 


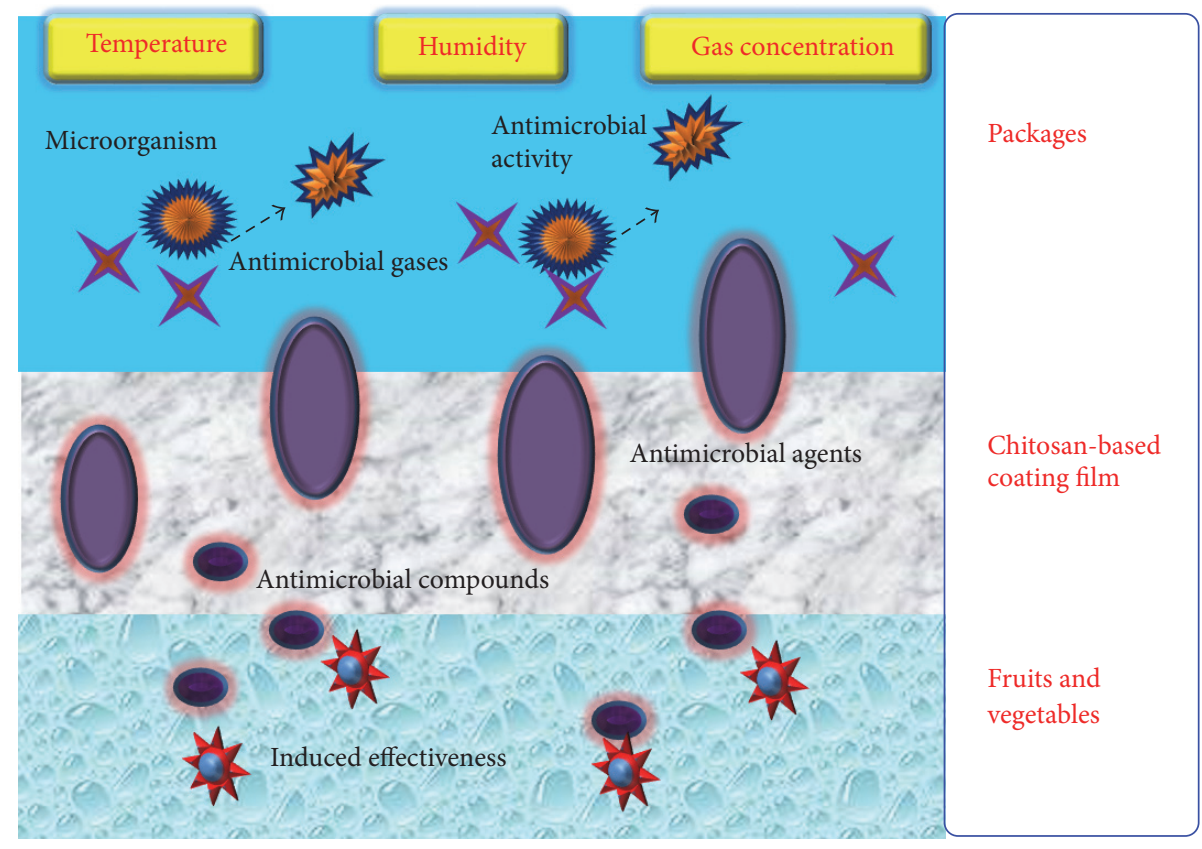

FIGURE 7: Preservation mechanism of chitosan-based coating on the quality of pulps $[57,176,177]$.

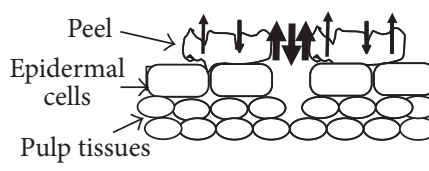

Fruits and vegetables without coating
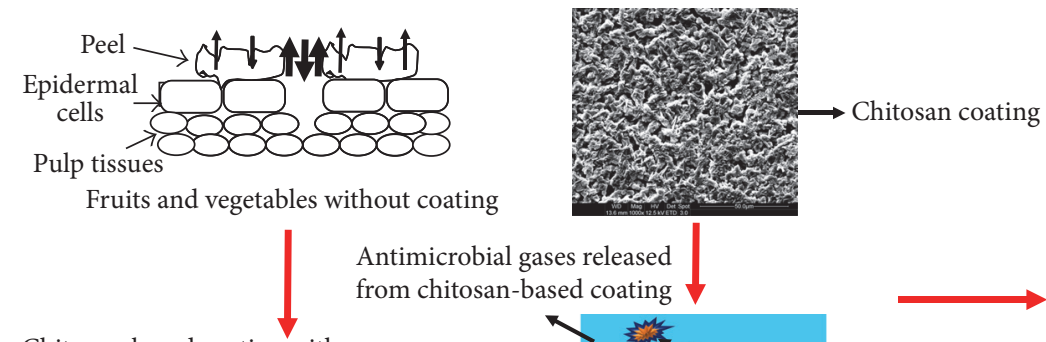

Antimicrobial gases released from chitosan-based coating

Chitosan-based coating with antimicrobial agents
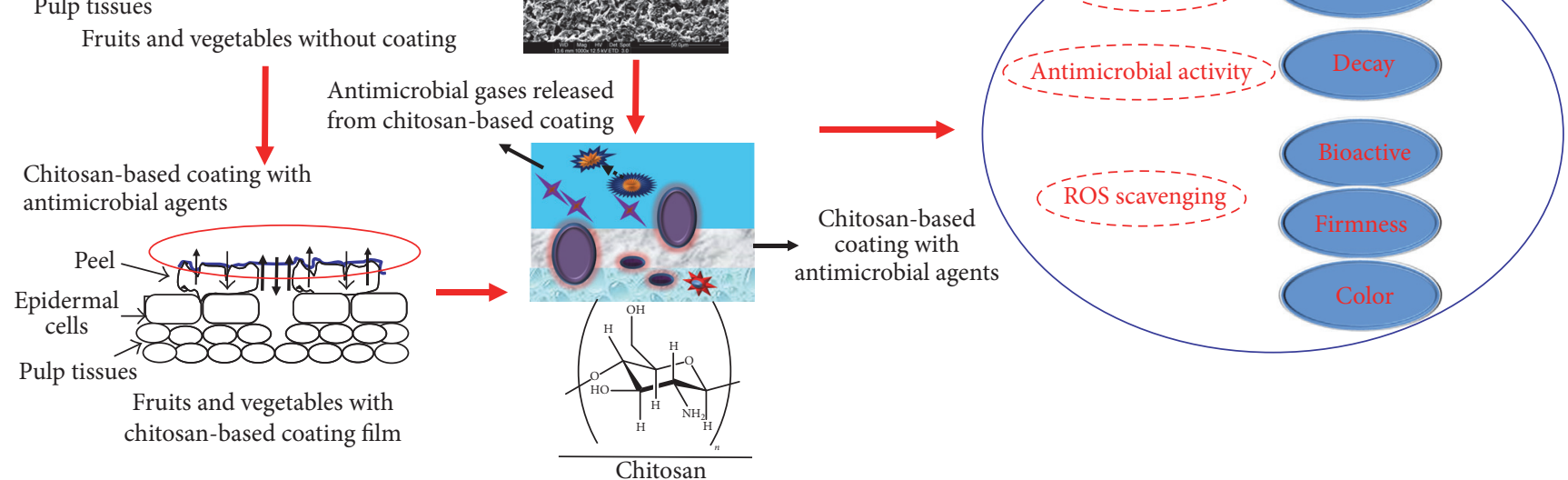

FIgURE 8: Preservation mechanism of chitosan-based coating on fruits and vegetables $[18,42,47,57,176,177]$.

indicated in Figures 7 and 8, the higher concentration of dioxide carbonate in the package might induce the anaerobic respiration of fruits and vegetables and generate the ethanol to influence their quality [118].

\subsection{Induction Defense Property of Chitosan Coating with} Antimicrobial Agents. During the storage period, reactive oxygen with the stronger oxidizing ability could cause deep harm for the cell membrane of fruits and vegetables, which is always eliminated by some defense enzymes, such as peroxidase (POD), superoxide dismutase (SOD), and catalase (CAT). SOD could decrease the concentration of toxic $\mathrm{H}_{2} \mathrm{O}_{2}$ through dismutation reaction and catalyze exclusively $\mathrm{O}_{2}{ }^{--}$ into nontoxic $\mathrm{O}_{2}$. Moreover, $\mathrm{H}_{2} \mathrm{O}_{2}$ might be catalyzed into $\mathrm{H}_{2} \mathrm{O}$ and $\mathrm{O}_{2}$ by the function of CAT or POD $[18,119]$. As indicated in Figure 7, the chitosan-based coating could reduce the free radicals, increase the disease resistance, and exhibit the good potential for inducing defense-related enzymes in the products of fruit and vegetable $[1,18,120]$. The inducing effectiveness of this coating might be also be affected by the addition of antimicrobials, such as cinnamon and clove oils, because of its antioxidant activity [2]. Chitosan coating with cinnamon oil has become a promising treatment for inducing the defense property of fruits and vegetables $[1,2,18,41]$. As reported by Tomida et al. [121], the scavenging 
activity of free radicals could be increased with increasing the used concentration and decreasing the molecular weight of chitosan. Furthermore, Hong et al. [122] reported that the treatment of chitosan could induce a significant increase in the activities of CAT and SOD and inhibit the production of superoxide free radical. It could also delay the changes in the contents of malondialdehyde (MDA) and chlorophyll of guava fruit [122]. The incorporation of grafted eugenol and carvacrol enhanced the antioxidative activity of chitosan $[36,122,123]$. Zhang et al. [83] also indicated that the complex coating of chitosan and salicylic acid could increase the activities of antioxidant enzyme in cucumber during storage. Moreover, the production of superoxide free radicals and MDA in the treated plums could also be controlled by the treatment of chitosan-based coating with ascorbic acid [124].

Many free radicals in the cell could be harmful to cell membrane by the destruction of equilibrium between elimination and production of the radical [88]. Lipid peroxidation is also poisonous to cell, which is an oxidation process of unsaturated fatty acid through free radical action [88]. The protective enzymes in fresh pulps always exhibit the high activities and the free radical in the cell of pulps, which might be rapidly eliminated after being treated with chitosan-based coating with active compounds, as shown in Figures 7 and 8 [122]. The content of MDA could harm the cell membrane and reflect the active status of free radical in the fruit because it is one of final products in lipid peroxidation reaction. The more the MDA content, the higher the level of free radical [18]. The cell membrane permeability might increase once being damaged, which induces the increase of the electrolyte leakage rate $[18,125]$. The increases of MDA content and cell membrane permeability could be controlled or restrained by the treatment of chitosan-based coating [18]. The fruits treated by the combined application of chitosan and heat treatment showed the lowest MDA and membrane leakage [115]. The antioxidative effect could occur with the peroxide free radicals in products after being treated by the chitosanbased coating with active substances. The mechanisms might be due to the transfer function of the free electron from the peroxide to the electron sink of chitosan and the antioxidant activity of active compounds in the carrier [126]. For the function of chitosan, the relative antioxidative effects might be due to the differences in intramolecular hydrogen bonding between amino and hydroxyl group.

\subsection{Physical Property of Chitosan-Based Coating with Antimi-} crobial Agents. Water vapor permeability rate is one important characteristic for the application of chitosan-based coating in order to evaluate the prevention function on the moisture losses of fruits and vegetables. It could be increased with prolonging the storage time, increasing the molecular weight of chitosan, enhancing the drying temperature, and decreasing the storage temperature. As reported by Kerch and Korkhov [127], lower water vapor permeability was found in the thinner chitosan-based coating films. Moreover, the increased water vapor permeability of composite gelatin/chitosan coatings might be due to the increase of coatings thickness [128]. The nanocomposite coating film of chitosan-Na-montmorillonite demonstrated a remarkable decrease in the water vapor permeability property [129]. A similar result was observed in the chitosan/montmorilloniteK10 nanocomposite films [130]. As reported by Abdollahi et al. [21], the incorporation of sun flower oil into chitosanbased carrier could improve the water vapor permeability. This effect might be due to the hydrophobic interactions and the clusters of hydrophobic masses on the surfaces of coating films [22]. The combined use of olive oil and cellulose nanoparticles could reduce the water vapor permeability of chitosan-based films [131]. Due to the nonpolar nature of the lipid in the chitosan-based coating film, the water vapor permeation could decrease with increasing the oil concentration [132]. As reported by Souza et al. [133], the resistance to the water vapor diffusion of chitosan films could be increased by adding the carp oil. On the other hand, Zhang et al. [134] indicated that chitosan films containing lavender oil exhibited lower water vapor permeability. The decreasing moisture sorption of chitosan coating film was observed with increasing concentration of olive oils [132]. The incorporation of gallic acid could also decrease the water vapor permeability of chitosan coating films [113].

The addition of antimicrobial agents could influence the mechanical property of chitosan-based coating. The coating film of chitosan combined with acetic acid exhibited the highest tensile strength and the lowest percentage elongation [127, 135]. Pereda et al. [132] reported that the tensile properties of chitosan coating film could be improved with increasing the concentration of olive oil. This might be due to the interactions between lipid and carbohydrate phases and the lubricant characteristics of oil [132]. The investigation of Bedel et al. [97] also reported that the application of chitosan combined with poly(ethylene glycol) or sodium bicarbonate could be able to create the formation of desired pore in the coating systems. The zein/chitosan composite films incorporated with the phenolic compounds and dicarboxylic acids could exhibit better mechanical properties [136]. Ojagh et al. [137] also demonstrated that the effect of cinnamon oil on chitosan film might decrease its elongation at break. This might be due to the strong interaction between the polymer and cinnamon oil, which could produce a cross-linker effect and decrease the molecular mobility and the free volume of chitosan polymer. The arrangement of stacking layers of cinnamon in chitosan film indicated that the formed compact structure could induce the increase in the tensile strength and the decrease in elongation at break.

4.4. Surface and Structural Characterization of ChitosanBased Coating. The surface structure and the loading capacity of antimicrobial agents are very important for the application of coating films. Therefore, the structural characterization and surface observation were investigated and reported by several researchers. The microstructure of chitosan coating was observed by AFM and SEM in the investigation of Xing et al. [1, 2, 18]. They reported that the distribution of micropores might be inhomogeneous on the surface of chitosan-based coating film. Xing et al. [18] displayed the plane and the three-dimensional profiles for the surface of 
chitosan-based coating film. The micropore microstructure was found on the surface of chitosan-based samples. The analysis of AFM on the surface and microstructure of chitosan-based coating was also conducted and the result images were shown in Figure 9. The parameters $R_{a}$ and $R_{q}$ were always used to analyze the surface roughness of coating film, which indicated the mean roughness and the root mean square of $Z$ data in the AFM analysis, respectively. The chitosan membrane with micropores could be used as the carrier of antimicrobial agents, which might fill the empty spaces of micropores in the films. This microstructure could moderate the passing through of $\mathrm{O}_{2}$ and $\mathrm{CO}_{2}$ and prevent the water loss from the surfaces of fruit $[2,18]$. However, as reported by Valenzuela et al. [22], SEM images indicated that the superficial structures of chitosan and chitosanquinoa protein extracts $(\mathrm{pH} 8)$ films were homogeneous and without pores. This might be due to the different sources and property of chitosan and the interaction of additives and chitosan. On the other hand, the structure of microcracking matrices and micropores with different sizes was observed after the addition of sun flower oil blends as $2.9 \mathrm{~g} / 100 \mathrm{~mL}$ into the chitosan-quinoa protein extracts $(\mathrm{pH} 8)$ blend film. The results of Song et al. [89] indicated that the diffused network of nanosilica in chitosan matrix was generated by the formation of $\mathrm{Si}-\mathrm{O}-\mathrm{C}$ bonds and hydrogen bonds. TEM results indicated that the highly porous structure was observed in the chitosan/nanosilica film. Flores et al. [86] reported that chitosan coating emulsions obtained by the high-pressure homogenization method could reduce its apparent viscosity and the droplet size. This chitosan film could display better stability characteristics and surface properties that make them suitable as a coating for the storage of fruit and vegetable products.

The investigation of Cai et al. [29] analyzed the structure characteristics of chitosan-based coating film by differential scanning calorimetry and fourier transform infrared spectroscopy (FTIR). Results indicated that the absorbance bands at $3438 \mathrm{~cm}^{-1}$ of chitosan-Ac (acetate) and $3422 \mathrm{~cm}^{-1}$ of nisin were due to $\mathrm{O}-\mathrm{H}$ stretching vibrations. It demonstrated that the hydrogen bond was formed between chitosan and nisin. On the other hand, their results also displayed that the absorb bands at $1645 \mathrm{~cm}^{-1}$ of chitosan-Ac and $1659 \mathrm{~cm}^{-1}$ of nisin were assigned to $\mathrm{C}=\mathrm{O}$ stretching vibrations of the amide I band, which indicated that the electrostatic interaction occurred between nisin and chitosan used in the preparation process. Thermal analysis indicated that the exothermic peak of chitosan/nisin $\left(286^{\circ} \mathrm{C}\right)$ was shifted to a lower temperature compared with chitosan $\left(306^{\circ} \mathrm{C}\right)$. Han et al. [68] also confirmed the chemical structure of chitosan derivative by FTIR. The X-ray pattern of chitosan derivative indicated an obvious disappearance or shift of crystalline peaks compared to that of chitosan. Thermogravimetric analysis suggested that the degradation peak temperature of chitosan was much lower than that of thiolated chitosan derivative. Moreover, in the investigation of Shi et al. [88], the nanostructural organization of the chitosan/silica xerogel hybrid membrane was observed by TEM. They indicated that the chitosan/nanosilica coating exhibited highly porous structure. The investigation of Abdollahi et al. [21] about the X-ray diffraction characterization indicated that the crystalline structure of chitosan was strongly affected by its origin and molecular constitution, as well as its processing treatment. The results of FTIR for these chitosan/montmorillonite nanocomposite films noted that the peaks between 3500 and $3000 \mathrm{~cm}^{-1}$ might be related to the stretching vibration of free hydroxyl and to asymmetric and symmetric stretching of the N-H bonds in the amino group. Two strong bands at 1541 and $1403 \mathrm{~cm}^{-1}$ were less discernible in the coating with clay and rosemary essential oil, which might be associated with $\mathrm{OH}$ in-plane bending. These peaks flattened more with incorporating clay and rosemary essential oil. This may be due to the hydrogen bonding among the -OH group in montmorillonite, functional groups in rosemary essential oil ingredients, and the $-\mathrm{NH}$ and $-\mathrm{OH}$ groups in chitosan. FTIR results demonstrated that the hydrogen bonds might be formed by the electrostatic interaction between the cationic groups of $\mathrm{CH}$ and the anionic groups of quinoa protein. The investigation of Valenzuela et al. [22] also analyzed the X-ray diffraction patterns of chitosan coating films. Results displayed that the diffractogram of chitosan film showed partially crystalline nature. Moreover, the intensity of the diffraction-pattern peaks also indicated that the introduction of sun flower oil into the film matrix might generate a less crystalline structure [22].

\section{Application of Chitosan-Based Coating on the Storage of Fruits and Vegetables}

Chitosan-based coatings could be used as a carrier for antimicrobial agents and a protective barrier to reduce respiration rates, control the microbial growth and color changes, maintain the storage quality, and prolong the shelf life of fruits and vegetables, such as red pitayas, apples, table grapes, pear, peppers, tomato, lotus root, and mushroom [1, 2, 41].

Chien et al. [138] had applied the chitosan coating with low molecular weight to keep the quality and extend the shelf life of fresh-cut red pitayas. This coating could slow the reduction in sensory quality and maintain the contents of soluble solid, titratable acidity, and ascorbic acid in fruits. Results also demonstrated that the coating of chitosan with low molecular weight could inhibit the growth of microorganisms on sliced red pitayas.

The investigation of Sun et al. [139] demonstrated that the combination of chitosan coating with ascorbic acid improved the preservation quality of litchi fruit during postharvest storage period. The activities of polyphenol oxidase (PPO) and POD were decreased in coated fruits. The activities of SOD and the contents of ascorbic acid were increased in treated fruit, which also exhibited the low contents of hydrogen peroxide and MDA.

Hong et al. [122] suggested that the treatment of chitosan could significantly control the loss of firmness and delay the changes in the contents of MDA and chlorophyll in the guava fruits. This treatment could induce the increase in the activities of POD, SOD, and CAT and inhibit the production of superoxide free radical in fruits. Result indicated that the 


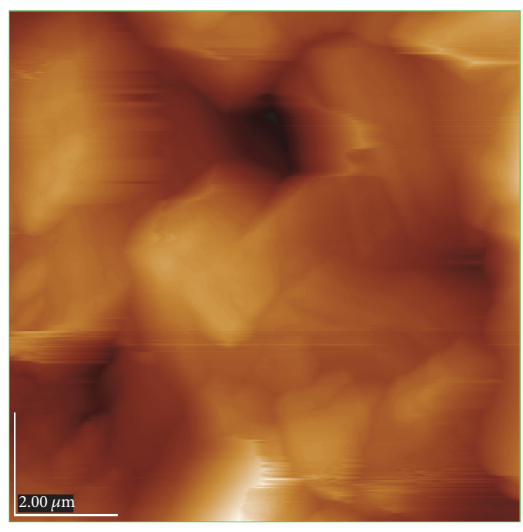

(a)

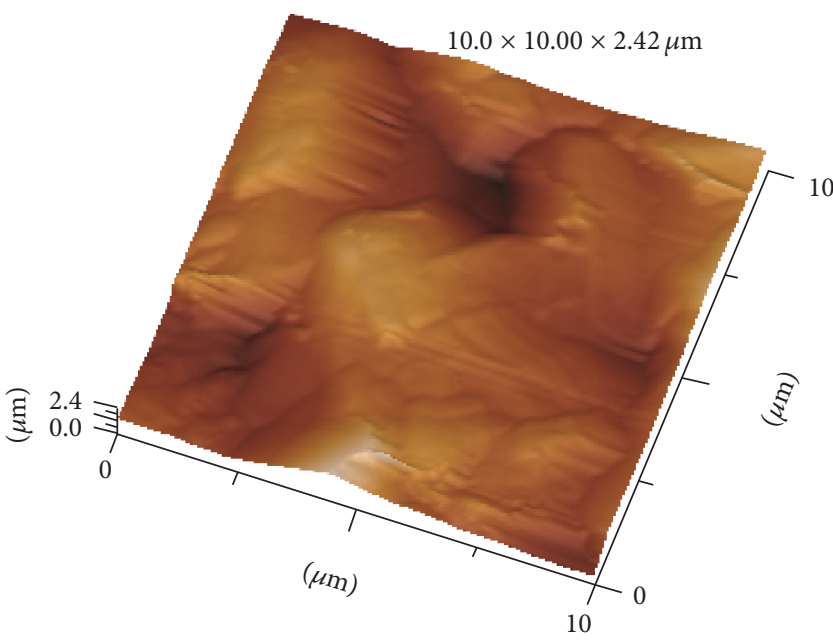

(b)

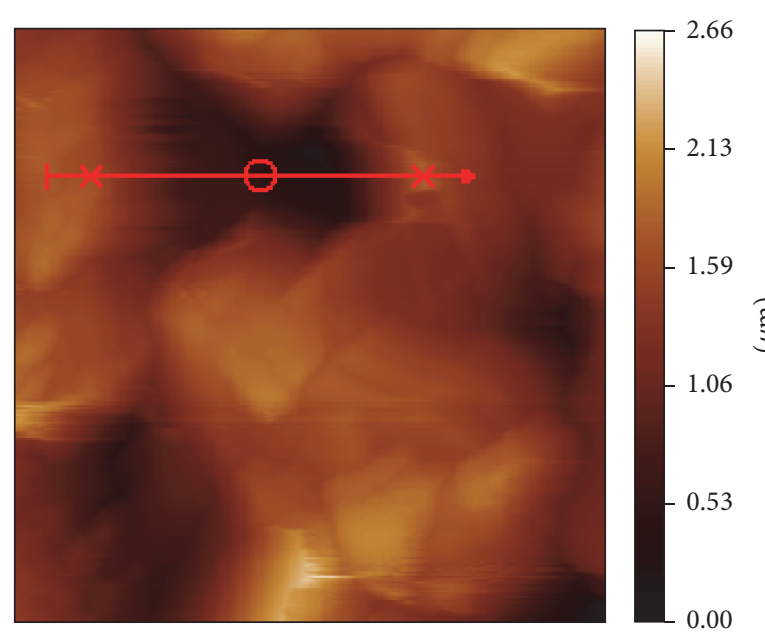

AFM AC

Size: $10.0 \times 10.00 \mu \mathrm{m}$
Ref: $-5.075 \mathrm{~V}$ Bias: $0.000 \mathrm{~V}$

$$
\begin{array}{ll}
\text { Profile information } & \\
R_{a}=0.453 \mu \mathrm{m} & R_{z \text { jis }}=1.21 \mu \mathrm{m} \\
R_{z}=1.53 \mu \mathrm{m} & \text { Length }=7.13 \mu \mathrm{m} \\
R_{q}=0.498 \mu \mathrm{m} &
\end{array}
$$

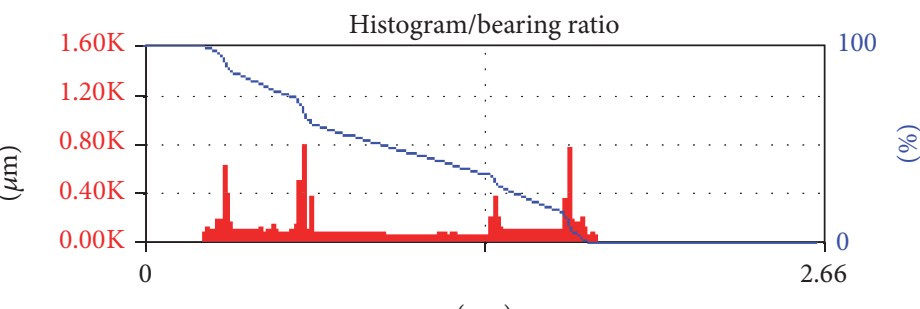

$(\mu \mathrm{m})$

$\begin{array}{ll} & 1 \\ Z_{1} \bullet(\mu \mathrm{m}) & 1.67 \\ Z_{2} \square(\mu \mathrm{m}) & 1.77 \\ \left|Z_{1}-Z_{2}\right|(\mu \mathrm{m}) & 0.100 \\ \text { Length }(\mu \mathrm{m}) & 5.57 \\ \text { Angle }(\mathrm{deg}) & 1.03\end{array}$

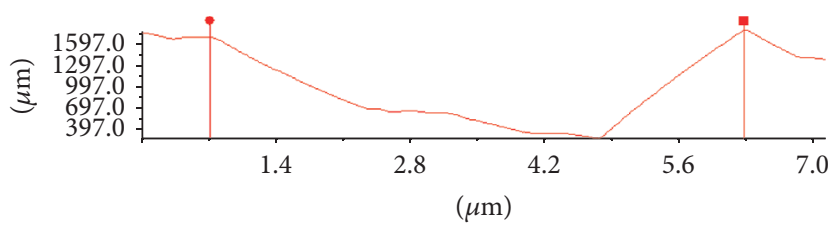

(c)

Figure 9: Continued. 


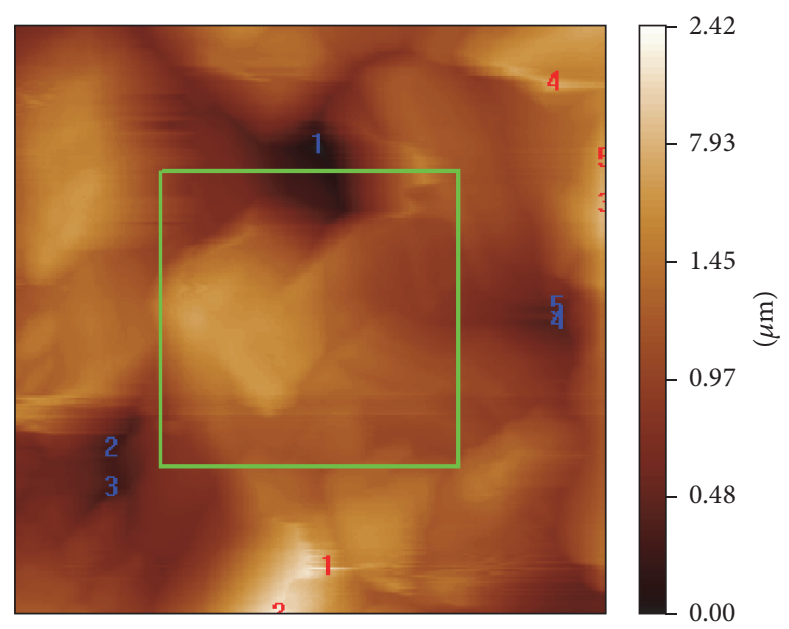

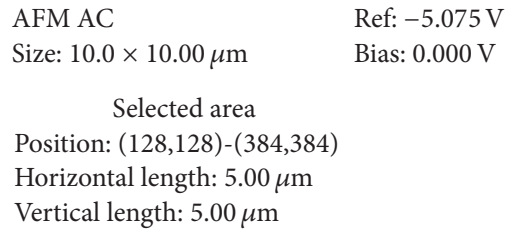
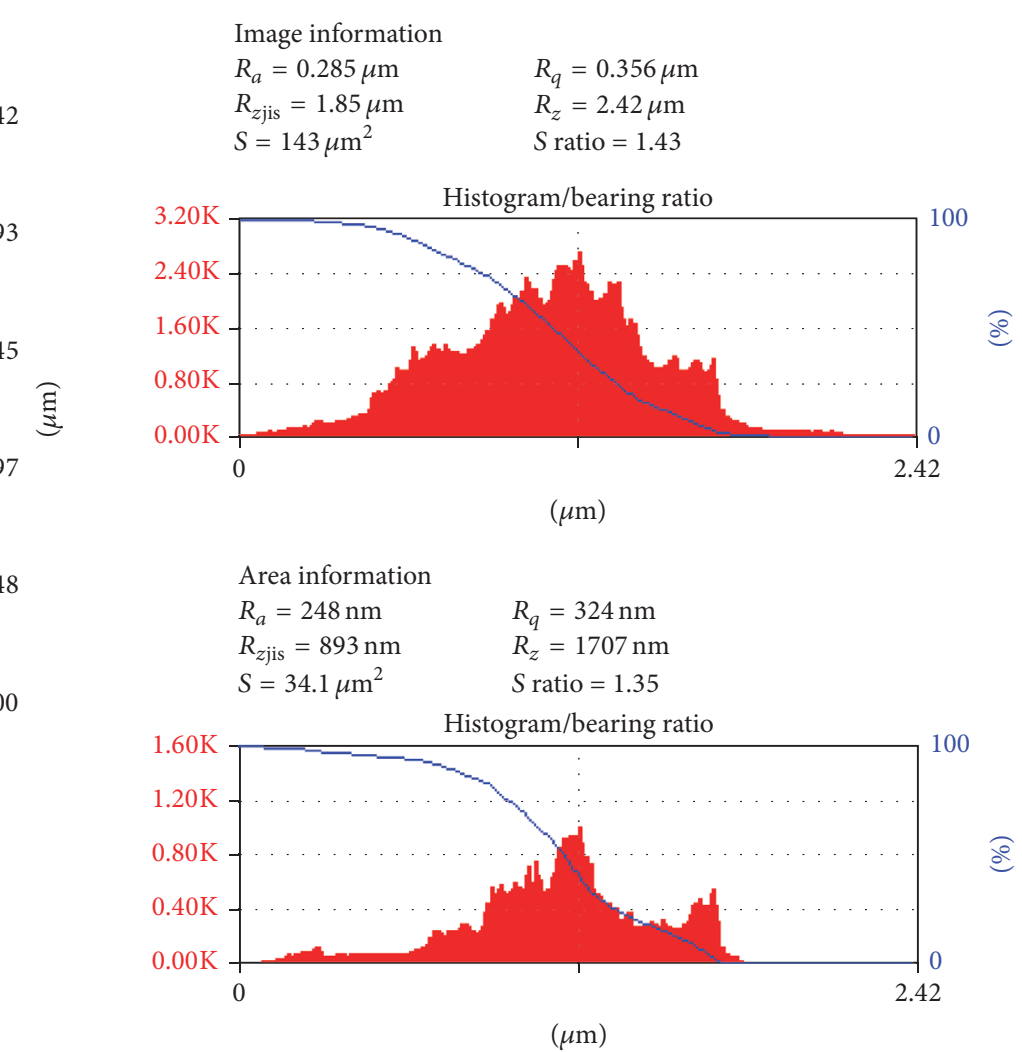

(d)

FIGURE 9: Morphological and roughness analysis of chitosan-based coating by AFM ((a) AFM plane profile; (b) AFM three-dimensional profile; (c) AFM profile information; (d) AFM image information) [57].

effect of chitosan on the increase of antioxidant ability might be helpful for slowing the ripening process of guava fruit.

Gao et al. [117] reported that the chitosan-glucose complex coating was effective for inhibiting the senescence and diseases of table grapes. This combined coating could decrease the decay and control the respiration rate and POD and SOD activities of fruits. It could also ensure the high sensory scores and extend the shelf life for grape fruits. dos Santos et al. (2012) suggested that the application of chitosan coating with Origanum vulgare L. essential oil could inhibit the fungi growth on grape fruits [12].

In this investigation of Shi et al. [88], the coating of chitosan with nanosilica could significantly reduce the weight loss, retard the browning index, and inhibit the increase of MDA content and PPO activity in longan fruit. The decreases in the contents of titratable acidity were controlled by this coating.

This investigation of Saxena et al. [140] was conducted in order to evaluate the quality changes of fresh-cut jackfruit bulbs treated with $\mathrm{CaCl}_{2}$, ascorbic acid, citric acid, sodium benzoate, and chitosan coating. Results indicated that this combined treatment could reduce the loss of ascorbic acid and restrict the microbial load on fruit samples.

$\mathrm{Xu}$ et al. [41] suggested that the application of oil fumigation and chitosan coating could keep the microbiological safety of fresh-cut pears. The smallest changes in the contents of vitamin $\mathrm{C}$ and total phenolic were observed in the slices coated by chitosan solution, which could also inhibit the PPO activity of pear slices. Xiao et al. [77] indicated that the chitosan coating with rosemary extracts might maintain the sensory attributes for fresh-cut pears. The treatment of calcium chloride, chitosan, and pullulan coating could influence the antioxidant activity of pears [141].

Han et al. [142] showed that the chitosan coating was effective in reducing the respiration rate and weight loss of sponge gourd, which could maintain the firmness, visual appearance, ascorbic acid content, and total phenolics content in fruit pulps. The chitosan treatment could markedly suppress the activities of POD and phenylalanine ammonialyase in sponge gourd fruits.

El-Eleryan et al. [143] reported that the dipping of Washington Navel orange fruit in chitosan-based solution was more effective in decreasing its weight loss. Coating with chitosan and green tea was the better method to reduce fruit decay, chilling injury, and POD activity. This treatment could maintain the higher contents of ascorbic acid and soluble solids in fruits.

Ibrahim et al. [144] demonstrated that pineapple fruits without visual fungal growth and with better eating quality were found in the treatment of chitosan during whole storage period. The application of irradiated chitosan coating was more effective for maintaining the ascorbic acid content in 
the first 15 days of storage and keeping the storage quality of pineapple.

Suseno et al. [145] reported that the banana samples coated by chitosan with $80 \%$ degree of deacetylation demonstrated the low losses of vitamin C. The losses of weight and vitamin $\mathrm{C}$ could decrease with increasing the chitosan concentration and deacetylation degree of chitosan. The results demonstrated that the coating of chitosan with $80 \%$ degree of deacetylation might be the most suitable solution for banana.

Liu et al. [124] reported that plums treated with the combination of chitosan and ascorbic acid exhibited a significantly lower activity of PPO and higher activities of SOD, CAT, and POD during the whole storage period. The combination of chitosan and ascorbic acid could inhibit the anthocyanin synthesis and decrease the activity of phenylalanine ammonia-lyase (PAL) in fruits.

Plainsirichai et al. [146] investigated that the chitosan coating could control the weight loss and reduce the disease incidence of rose apple fruits. Higher firmness of rose apples coated with chitosan was found compared to that of the control samples.

Petriccione et al. [147] reported that the chitosan coating could significantly delay the changes in color, ascorbic acid content, and respiration rate of sweet cherry. This treatment prolonged its postharvest life and maintained its nutraceutical value. The similar results on the strawberry fruits were also observed by Petriccione et al. [148]. Velickova et al. [90] also indicated that the coating of chitosan could decrease the senescence, modify the respiration rates, and slow down the metabolism of cherry.

Gol et al. [149] reported that the chitosan coating exhibited positive effects on the inhibition of cell wall degrading enzyme activities in carambola fruits. The fruits coated with chitosan exhibited good visual quality after 12 days of storage.

Xing et al. [2] demonstrated that the chitosan-based coating with cinnamon oil reduced the weight loss and decay of jujube fruits. The decrease in the contents of vitamin C and titratable acid could be inhibited by chitosan-oil coating, which also influenced the activities of PPO and the MDA content in fruits. Higher activities of scavenger antioxidant enzymes, lower activity of PAL, and the increased MDA content were also observed in the coated jujubes by other researchers $[27,34,150]$. Chitosan coating with ultraviolet irradiation could also delay the decline of ascorbic acid content in jujube fruits [151].

Ban et al. [152] demonstrated that the application of chitosan coating combined with the heat treatment could maintain the higher levels of ascorbic acid and antioxidant capacity as well as the lower decay level than that for the untreated wolfberry fruits. The synergistically treated fruits also exhibited a higher acceptability and the good quality of wolfberry fruits after cold storage.

The investigation conducted by Sabaghi et al. [92] investigated the effects of chitosan-based coatings incorporated with the green tea extract on the lipid oxidation, fungal growth, and sensory properties of walnut kernels. The inhibition effective for fruits was found on the oxidation of lipid but not on the growth of fungi.
Souza et al. [153] indicated that the lower values of mass loss, browning, and higher titratable acidity were observed in the mangoes treated by chitosan nanomultilayer coating. As reported by Medeiros et al. [154], effect of the coating of chitosan and pectin has been found on the consequent extension of the shelf life of mangoes. Cissé et al. [155] indicated that chitosan coatings with lactoperoxidase could inhibit the fungal proliferation and the ripening of mango. It provided a beneficial effect on the contents of total soluble solids and ascorbic acid of fruits.

Waewthongrak et al. [156] reported that the application of chitosan with crude extract from the culture medium of Bacillus subtilis showed a significant reduction of fruit decay. It was clearly demonstrated that the $B$. subtilis itself and its crude extract and chitosan each induced the activities of POD in the infected flavedo tissues of mandarin fruits.

Chong et al. [157] reported that the combined treatment of chitosan and calcium chloride was the most effective to control the weight loss decrease, keep in firmness, and inhibit the mesophilic and psychrotrophic growths during storage. This edible coating with calcium chloride might extend the shelf life of fresh-cut honeydew melon.

Song et al. [89] reported that the use of chitosan/ nanosilica coating significantly delayed the browning and weight loss of loquat fruit, which also inhibited the decrease of titratable acidity in fruits. In the coated fruits, activities of PAL, PPO, and lipoxidase were inhibited. This coating could be effective in enhancing the chilling tolerance and extending a longer life of loquat fruit.

Duran et al. [158] developed the chitosan coatings with nisin, natamycin, pomegranate, and grape seed extract in order to maintain the quality of strawberry. Chitosan coating with natamycin could reduce the $\mathrm{O}_{2}$ consumption of fruits and exhibit better effects on delaying the changes of total soluble solid content and controlling the growth of microbial counts for fruits. The high antimicrobial activities of chitosan coatings with natamycin and with pomegranate were found against bacteria, yeast, and mold. Khalifa et al. [94] reported that the chitosan-based coating enriched with olive wastes polyphenols could control the increase of malondialdehyde and decay in coated strawberry fruits during cold-stored time. The addendum of olive leaves extract into chitosan coating significantly reduced the gradual decline in total phenolics, flavonoids, antioxidants, ascorbic acid, and MDA of strawberry. Wang and Gao [159] indicated that the treatment of chitosan could maintain the higher content of phenolics and anthocyanins in strawberries.

Zhou et al. [160] indicated that combination of chitosan and Pichia membranifaciens could inhibit the infections of Colletotrichum gloeosporioides on citrus fruits. It could also control the mycelial and spore germination growth of $C$. gloeosporioides. This inhibiting effect might be due to the interactions among chitosan, P. membranifaciens, C. gloeosporioides, and the citrus fruits.

The investigation by Kaya et al. [40] reported that the use of chitosan with acetic acid could keep the better quality of red kiwifruit berries. The changes in the weight loss, firmness, total polyphenol content, and ascorbic acid content were evaluated for coated fruits. Results revealed that the 
chitosan-based coating could become an effective technology in enhancing the quality and extending the short life of red kiwifruit berries.

Vieira et al. [93] confirmed that the treatment of chitosanbased coatings with Aloe vera liquid fraction could reduce water loss levels and keep the microbiological safety of coated blueberries after $25 \mathrm{~d}$ storage time. Yang et al. [161] indicated that the higher content of total phenolics was observed in blueberries treated with chitosan coatings with the extracts of blueberry leaf. According to Sun et al. [162] and Abugoch et al. [163], chitosan coating with essential oils was developed to extend the storage life of fresh blueberries. Chiabrando and Giacalone [164] also reported that chitosan coating could decrease the microbial growth rate of berries fruits.

The investigation of Carvalho et al. [165] indicated that the complex coating of chitosan with trans-cinnamaldehyde might improve the firmness and color and maintain the contents of vitamin $\mathrm{C}$ and carotenoid of fresh-cut melon slices, which could prolong its shelf life up to 15 days. This coating also reduced the levels of hydrogen peroxide radical and leaded to low lipid peroxidation degree and electrolyte leakage levels in fruits samples. The high visual quality and the low browning-associated enzymes were also found in the treated melon slices.

The investigation of $\mathrm{Ma}$ et al. [38] indicated that the composite coating of chitosan, LAE, cinnamon oil, and EDTA could control the growth of inoculated foodborne pathogens on the whole cantaloupes during storage. This coating could inhibit the redness and yellowness of cantaloupes.

The investigation of Xing et al. [17] reported that the chitosan-based coating could slow the respiration rate and prevent the browning of lotus root slices in packages. The application of chitosan combined with modified atmosphere packaging could exhibit the lowest PPO activity and the highest sensorial quality in the slices at the end of storage.

Jiang et al. [34] suggested that the chitosan-glucose coating could inhibit the increase of respiration rate and reduce the microorganism counts in the coated shiitake mushroom. This coating also delayed the changes of ascorbic acid and soluble solids level and maintained the better overall quality of mushroom.

The investigation of Pushkala et al. [166] explored the chitosan coating to extend the shelf life of shredded radish. The fruits treated by chitosan exhibited lower degree of weight loss, respiration rate, and soluble solids and higher phytochemicals content than those in control samples. The better sensory acceptability and lower microbial load were observed in the treated samples. This coating could be used as an efficient technique for keeping the quality of radish shreds.

Alvarez et al. [167] indicated that the treatment of chitosan with essential oils could improve the microbial safety of broccoli. Result indicated that this coating was a good alternative for controlling the survival of E. coli and Listeria monocytogenes present in broccoli and could not introduce the deleterious effect on the sensory quality.

The investigation of Mustafa et al. [168] displayed that the chitosan treatment could enhance the phenolic content in tomatoes, which also delayed the ripening and maintained the level of respiration. Moreover, Saha et al. [169] also reported that the combined application of chitosan and whey protein film could delay the decrease of ascorbic acid content in potato tubers.

The investigation of Chen et al. [170] indicated that the chitosan-based coating with methyl jasmonate was effective in reducing the disease incidence and lesion diameter of postharvest decay of cherry tomato. This coating resulted in higher activities of PPO, POD, and PAL than that of the control samples.

Li et al. [91] demonstrated that the molecular weight of chitosan could affect the DPPH radical scavenging activity of chitosan-maltose Maillard reaction products (MRP). Maltose-high molecular weight chitosan MRP showed the better effects on inhibiting the activity of PPO, alleviating declines of total soluble solids content in fresh-cut Typha latifolia L.

Zhang et al. [83] indicated that the coating of chitosan$g$-salicylic acid could better inhibit the chilling injury of cucumber. They reported that coating of chitosan- $g$-salicylic acid could reduce the weight loss and limit the increases of MDA content and electrolyte leakage in cucumber. Moreover, this chitosan-based coating could increase the activities of antioxidant enzymes such as SOD and CAT in cucumber during storage.

Yang et al. [171] demonstrated that the combined application of chitosan coating and $\mathrm{ClO}_{2}$ could inhibit the increase of respiration rate and maintain the firmness, delay the browning, and reduce the microorganism counts of freshcut bamboo shoot. Furthermore, this combined coating could inhibit the activities of PPO, POD, and PAL during the storage period. The treatment of chitosan-based coating with $\mathrm{ClO}_{2}$ might be the promising method to prolong the life of freshcut bamboo shoot.

Ali et al. [23] reported that chitosan-based coating with lemongrass essential oil could maintain the quality of bell pepper throughout the storage. The in vivo results demonstrated that the application of chitosan-based coating incorporated with essential oils was significantly better to maintain the quality of pepper. As indicated by Xing et al. [18], the application of chitosan coating with cinnamon oil could exhibit the best control effects on the pepper decay and the loss of sensory acceptability and provide the benefit for the higher activities of scavenger antioxidant enzymes in the pepper. The contents of MDA and electrolyte leakage in coated peppers were lower than that in the control samples. Poverenov et al. [128] indicated that the composite chitosangelatin coating could control the microbial decay, enhance fruit texture, and prolong the possible period of cold storage up to 21 days.

Wang et al. [71] reported that chitosan could provide the effective inhibition on the Sclerotinia rot of carrot, which might induce the activity of defense-related enzymes, such as PPO and POD. These results should be due to the property of chitosan including its antimicrobial activity and its induction of defense response in carrot. Simões et al. [172] demonstrated before that the application of chitosan coating might reduce the surface whiteness and preserve the sensory quality of carrot sticks during storage. The chitosan edible coating could moderate the levels of $\mathrm{O}_{2}$ and $\mathrm{CO}_{2}$ in the package and 
maintain quality of carrot sticks during storage. Pushkala et al. [173] showed that the chitosan-citric acid coating was found to be beneficial in reducing weight loss, controlling the changes in total soluble solid content, and exhibiting the lower respiration rate of carrot. It could also maintain its total phenolic content and sensory and microbial safety after 10 days of storage.

Qiu et al. [174] indicated that chitosan with the low or the high molecular weight could inhibit the radial growth of Fusarium concentricum, which was separated from the postharvest green asparagus. Their results also indicated that any apparent sign of phytotoxicity was not found in the coated asparagus. The chitosan coating with low and high molecular weight could keep the good quality over 28 days during the cold storage time.

Mohammadi et al. [25] suggested that the chitosan-based coating with Cinnamomum zeylanicum essential oil could improve the physicochemical quality and microbiological safety of cucumbers during storage. The coated cucumber fruits expressed the better quality of being firmer, the maintained color, and the lower microbial counts. Its shelf life could also extend up to $21 \mathrm{~d}$ at $10^{\circ} \mathrm{C}$.

Guerra et al. [78] demonstrated that the chitosan-based coatings with Mentha piperita L. or Mentha $\times$ villosa Huds might delay the growth of artificial inoculated fungi in tomato fruit during the whole storage time. These composited coatings could preserve the quality and control the mold infections of cherry tomato fruit.

These above works indicated that these chitosan-based coatings enriched with antimicrobial agents can delay the rate of respiration, decrease weight loss, and keep the nutrients and sensory quality of fruits and vegetables. The impact of these coatings has also been described on the shelf life and the microbiological infection of agricultural products during storage.

\section{Future Trends of Chitosan-Based Coating with Antimicrobial Agents}

The use of nanosized particles as the antimicrobial agents incorporated into the chitosan coating is very interesting for many researchers. More studies are necessary to develop the chitosan-based coating with nanoparticles in order to understand the interactions between nanosized particles and coating materials [84].

The thick coating film on the surface of fruits and vegetables becomes an undesirable barrier for restricting the exchange of respiratory gases. It is necessary to adjust its thickness and improve its delivery properties. More research is needed to resolve the problems of coating, such as high sensitivity to humidity and unsatisfactory mechanical property.

The chitosan-based coating with a known allergen on the food products should be clearly understood and labeled. This is because of the fact that chitosan coatings with many kinds of antimicrobial agents are made from ingredients that might cause the allergic reaction on the surface of fruits and vegetables, especially for fresh-cut slices. Further research on this point is needed.
Other works that need to be done are to produce the chitosan with consistent properties and establish the related standards for its application [175]. The preparation and application of chitosan-based coating should be conducted on a commercial trial. Moreover, the lower cost of coating films should be developed.

\section{Conclusion}

To effectively keep the storage quality and prolong the shelf life of fruits and vegetables, the chitosan-based coating with antimicrobial agents is increasingly developed as a relatively convenient and safe measure in recent years. The preparation, property, mechanism, and application effectiveness on the fruits and vegetables of chitosan-based coating with antimicrobial agents were reviewed. The chitosan-based coatings with essential oils, acid, and nanoparticles were developed by other researchers. The antimicrobial activity, functional properties, and surface and mechanical properties of chitosanbased coating film are very important for its application on the storage of fruits and vegetables, which were investigated by many researchers before and introduced in this context. Results reported by many researchers demonstrated that the application of chitosan-based coating with different antimicrobial agents might become an interesting technology to prevent the quality loss of postharvest fruits and vegetables.

\section{Competing Interests}

The authors declare that they have no competing interests.

\section{Acknowledgments}

This work is supported by the Innovation Team Construction Program of Sichuan Education Department (15TD0017), Key Laboratory Open Research Fund of Grain and Oil Processing and Food Safety of Xihua University (szjj2015003, szjj2014-003, and szjj2014-002), Key Laboratory Open Research Fund of Physiological and Storage of Agricultural Products of Agriculture Ministry (KF008), National Natural Science Foundation of China (31501547), Tianjin Project of Natural Science Fund (13JCYBJC25600), Science and Technology Support Program of Sichuan (2016FZ0019), and Young Scholars Training Plan of Xihua University (01201413).

\section{References}

[1] Y. Xing, Q. Xu, Z. Che, X. Li, and W. Li, "Effects of chitosanoil coating on blue mold disease and quality attributes of jujube fruits," Food \& Function, vol. 2, no. 8, pp. 466-474, 2011.

[2] Y. Xing, Q. Xu, L. Jiang et al., "Effect of different coating materials on the biological characteristics and stability of microencapsulated Lactobacillus acidophilus," RSC Advances, vol. 5, no. 29, pp. 22825-22837, 2015.

[3] J. L. Duan and S. Y. Zhang, "Application of chitosan based coating in fruit and vegetable preservation: a review," Journal of Food Processing \& Technology, vol. 4, no. 5, article 277, 2013. 
[4] Y. W. Yu and Y. Z. Ren, "Effect of chitosan coating on preserving character of post-harvest fruit and vegetable: a review," Journal of Food Processing \& Technology, vol. 4, no. 8, article 254, 2013.

[5] X. Meng, J. Han, Q. Wang, and S. Tian, "Changes in physiology and quality of peach fruits treated by methyl jasmonate under low temperature stress," Food Chemistry, vol. 114, no. 3, pp. 1028$1035,2009$.

[6] S. Gualanduzzi, E. Baraldi, I. Braschi, F. Carnevali, C. E. Gessa, and A. De Santis, "Respiration, hydrogen peroxide levels and antioxidant enzyme activities during cold storage of zucchini squash fruit," Postharvest Biology and Technology, vol. 52, no. 1, pp. 16-23, 2009.

[7] R. Yinzhe and Z. Shaoying, "Effect of carboxymethyl cellulose and alginate coating combined with brewer yeast on postharvest grape preservation," ISRN Agronomy, vol. 2013, Article ID 871396, 7 pages, 2013.

[8] M. A. Gatto, A. Ippolito, V. Linsalata et al., "Activity of extracts from wild edible herbs against postharvest fungal diseases of fruit and vegetables," Postharvest Biology and Technology, vol. 61, no. 1, pp. 72-82, 2011.

[9] N. Mantilla, M. E. Castell-Perez, C. Gomes, and R. G. Moreira, "Multilayered antimicrobial edible coating and its effect on quality and shelf-life of fresh-cut pineapple (Ananas comosus)," LWT-Food Science and Technology, vol. 51, no. 1, pp. 37-43, 2013.

[10] E. S. Lago-Vanzela, P. do Nascimento, E. A. F. Fontes, M. A. Mauro, and M. Kimura, "Edible coatings from native and modified starches retain carotenoids in pumpkin during drying," LWT_Food Science and Technology, vol. 50, no. 2, pp. 420-425, 2013.

[11] Á. M. Lima, M. A. Cerqueira, B. W. S. Souza et al., "New edible coatings composed of galactomannans and collagen blends to improve the postharvest quality of fruits-influence on fruits gas transfer rate," Journal of Food Engineering, vol. 97, no. 1, pp. 101-109, 2010.

[12] N. S. T. dos Santos, A. J. A. Athayde Aguiar, C. E. V. de Oliveira et al., "Efficacy of the application of a coating composed of chitosan and Origanum vulgare L. essential oil to control Rhizopus stolonifer and Aspergillus niger in grapes (Vitis labrusca L.)," Food Microbiology, vol. 32, no. 2, pp. 345-353, 2012.

[13] P. K. Dutta, S. Tripathi, G. K. Mehrotra, and J. Dutta, "Perspectives for chitosan based antimicrobial films in food applications," Food Chemistry, vol. 114, no. 4, pp. 1173-1182, 2009.

[14] M. Aider, "Chitosan application for active bio-based films production and potential in the food industry: review," LWTFood Science and Technology, vol. 43, no. 6, pp. 837-842, 2010.

[15] N. A. Abbasi, Z. Iqbal, M. Maqbool, and I. A. Hafiz, "Postharvest quality of mango (Mangifera indica 1.) fruit as affected by chitosan coating," Pakistan Journal of Botany, vol. 41, no. 1, pp. 343-357, 2009.

[16] I. Tahiri, M. Desbiens, C. Lacroix, E. Kheadr, and I. Fliss, "Growth of Carnobacterium divergens M35 and production of Divergicin M35 in snow crab by-product, a natural-grade medium," LWT-Food Science and Technology, vol. 42, no. 2, pp. 624-632, 2009.

[17] Y. Xing, X. Li, Q. Xu, J. Yun, and Y. Lu, "Antifungal activities of cinnamon oil against Rhizopus nigricans, Aspergillus flavus and Penicillium expansum in vitro and in vivo fruit test," International Journal of Food Science and Technology, vol. 45, no. 9, pp. 1837-1842, 2010.

[18] Y. Xing, X. Li, Q. Xu, J. Yun, Y. Lu, and Y. Tang, "Effects of chitosan coating enriched with cinnamon oil on qualitative properties of sweet pepper (Capsicum annuum L.)," Food Chemistry, vol. 124, no. 4, pp. 1443-1450, 2011.

[19] M. Z. Elsabee and E. S. Abdou, "Chitosan based edible films and coatings: a review," Materials Science and Engineering: C, vol. 33, no. 4, pp. 1819-1841, 2013.

[20] A. Perdones, L. Sánchez-González, A. Chiralt, and M. Vargas, "Effect of chitosan-lemon essential oil coatings on storagekeeping quality of strawberry," Postharvest Biology and Technology, vol. 70, pp. 32-41, 2012.

[21] M. Abdollahi, M. Rezaei, and G. Farzi, "A novel active bionanocomposite film incorporating rosemary essential oil and nanoclay into chitosan," Journal of Food Engineering, vol. 111, no. 2, pp. 343-350, 2012.

[22] C. Valenzuela, L. Abugoch, and C. Tapia, "Quinoa proteinchitosan-sunflower oil edible film: mechanical, barrier and structural properties," LWT-Food Science and Technology, vol. 50, no. 2, pp. 531-537, 2013.

[23] A. Ali, N. M. Noh, and M. A. Mustafa, "Antimicrobial activity of chitosan enriched with lemongrass oil against anthracnose of bell pepper," Food Packaging and Shelf Life, vol. 3, pp. 56-61, 2015.

[24] R. Severino, G. Ferrari, K. D. Vu, F. Donsì, S. Salmieri, and M. Lacroix, "Antimicrobial effects of modified chitosan based coating containing nanoemulsion of essential oils, modified atmosphere packaging and gamma irradiation against Escherichia coli O157:H7 and Salmonella Typhimurium on green beans," Food Control, vol. 50, pp. 215-222, 2015.

[25] A. Mohammadi, M. Hashemi, and S. M. Hosseini, "Chitosan nanoparticles loaded with Cinnamomum zeylanicum essential oil enhance the shelf life of cucumber during cold storage," Postharvest Biology and Technology, vol. 110, pp. 203-213, 2015.

[26] L. Sánchez-González, C. Pastor, M. Vargas, A. Chiralt, C. González-Martínez, and M. Cháfer, "Effect of hydroxypropylmethylcellulose and chitosan coatings with and without bergamot essential oil on quality and safety of cold-stored grapes," Postharvest Biology and Technology, vol. 60, no. 1, pp. 57-63, 2011.

[27] Y. Yu, S. Zhang, Y. Ren, H. Li, X. Zhang, and J. Di, "Jujube preservation using chitosan film with nano-silicon dioxide," Journal of Food Engineering, vol. 113, no. 3, pp. 408-414, 2012.

[28] T. Sun, C.-L. Wu, H. Hao, Y. Dai, and J.-R. Li, "Preparation and preservation properties of the chitosan coatings modified with the in situ synthesized nano SiOx," Food Hydrocolloids, vol. 54, pp. 130-138, 2016.

[29] J. Cai, J. Yang, C. Wang, Y. Hu, J. Lin, and L. Fan, "Structural characterization and antimicrobial activity of chitosan (CS40)/nisin complexes," Journal of Applied Polymer Science, vol. 116, no. 6, pp. 3702-3707, 2010.

[30] S. Butot, T. Putallaz, R. Amoroso, and G. Sánchez, "Inactivation of enteric viruses in minimally processed berries and herbs," Applied and Environmental Microbiology, vol. 75, no. 12, pp. 4155-4161, 2009.

[31] W. J. Janisiewicz and W. S. Conway, "Combining biological control with physical and chemical treatments to control fruit decay after harvest," Stewart Postharvest Review, vol. 6, no. 1, pp. $1-16,2010$.

[32] Z. Cao and Y. Sun, "Chitosan-based rechargeable long-term antimicrobial and biofilm-controlling systems," Journal of Biomedical Materials Research-Part A, vol. 89, no. 4, pp. 960967, 2009.

[33] L. R. Martinez, M. R. Mihu, M. Tar et al., "Demonstration of antibiofilm and antifungal efficacy of chitosan against candidal 
biofilms, using an in vivo central venous catheter model," The Journal of Infectious Diseases, vol. 201, no. 9, pp. 1436-1440, 2010.

[34] T. Jiang, L. Feng, and J. Li, "Changes in microbial and postharvest quality of shiitake mushroom (Lentinus edodes) treated with chitosan-glucose complex coating under cold storage," Food Chemistry, vol. 131, no. 3, pp. 780-786, 2012.

[35] J. Postma, L. H. Stevens, G. L. Wiegers, E. Davelaar, and E. H. Nijhuis, "Biological control of Pythium aphanidermatum in cucumber with a combined application of Lysobacter enzymogenes strain 3.1T8 and chitosan," Biological Control, vol. 48, no. 3, pp. 301-309, 2009.

[36] F. Chen, Z. Shi, K. G. Neoh, and E. T. Kang, "Antioxidant and antibacterial activities of eugenol and carvacrol-grafted chitosan nanoparticles," Biotechnology and Bioengineering, vol. 104, no. 1, pp. 30-39, 2009.

[37] L. Sánchez-González, M. Cháfer, A. Chiralt, and C. GonzálezMartínez, "Physical properties of edible chitosan films containing bergamot essential oil and their inhibitory action on Penicillium italicum," Carbohydrate Polymers, vol. 82, no. 2, pp. 277-283, 2010.

[38] Q. Ma, Y. Zhang, F. Critzer, P. M. Davidson, and Q. Zhong, "Quality attributes and microbial survival on whole cantaloupes with antimicrobial coatings containing chitosan, lauric arginate, cinnamon oil and ethylenediaminetetraacetic acid," International Journal of Food Microbiology, vol. 235, pp. 103-108, 2016.

[39] I. Khalifa, H. Barakat, H. A. El-Mansy, and S. A. Soliman, "Improving the shelf-life stability of apple and strawberry fruits applying chitosan-incorporated olive oil processing residues coating," Food Packaging and Shelf Life, vol. 9, pp. 10-19, 2016.

[40] M. Kaya, L. Česoniene, R. Daubaras, D. Leskauskaite, and D. Zabulione, "Chitosan coating of red kiwifruit (Actinidia melanandra) for extending of the shelf life," International Journal of Biological Macromolecules, vol. 85, pp. 355-360, 2016.

[41] Q. Xu, Y. Xing, Z. Che et al., "Effect of chitosan coating and oil fumigation on the microbiological and quality safety of freshcut pear," Journal of Food Safety, vol. 33, no. 2, pp. 179-189, 2013.

[42] G. Kerch, "Chitosan films and coatings prevent losses of fresh fruit nutritional quality: a review," Trends in Food Science and Technology, vol. 46, no. 2, pp. 159-166, 2015.

[43] G. Romanazzi and E. Feliziani, "Use of chitosan to control postharvest decay of temperate fruit: effectiveness and mechanisms of action," in Chitosan in the Preservation of Agricultural Commodities, pp. 155-177, 2016.

[44] M. Friedman and V. K. Juneja, "Review of antimicrobial and antioxidative activities of chitosans in food," Journal of Food Protection, vol. 73, no. 9, pp. 1737-1761, 2010.

[45] D. K. Youn, H. K. No, and W. Prinyawiwatkul, "Physicochemical and functional properties of chitosans prepared from shells of crabs harvested in three different years," Carbohydrate Polymers, vol. 78, no. 1, pp. 41-45, 2009.

[46] E. S. Abdou, K. S. A. Nagy, and M. Z. Elsabee, "Extraction and characterization of chitin and chitosan from local sources," Bioresource Technology, vol. 99, no. 5, pp. 1359-1367, 2008.

[47] M. Banerjee, S. Mallick, A. Paul, A. Chattopadhyay, and S. S. Ghosh, "Heightened reactive oxygen species generation in the antimicrobial activity of a three component iodinated chitosansilver nanoparticle composite," Langmuir, vol. 26, no. 8, pp. 5901-5908, 2010.

[48] R. C. Goy, D. de Britto, and O. B. G. Assis, "A review of the antimicrobial activity of chitosan," Polimeros: Ciência $e$ Tecnologia, vol. 19, no. 3, pp. 241-247, 2009.
[49] W. S. Xia, P. Liu, J. L. Zhang, and J. Chen, "Biological activities of chitosan and chitooligosaccharides," Food Hydrocolloids, vol. 25, no. 2, pp. 170-179, 2011.

[50] M. L. Weiner, "An overview of the regulatory status and of the safety of chitin andchitosan as food and pharmaceutical ingredients," in Advances in Chitin and Chitosan, C. J. Brine, P. A. Sandford, and J. P. Zikakis, Eds., pp. 63-70, Elsevier, London, UK, 1992.

[51] [KFDA] Korea Food and Drug Administration, Food Additives Code, KFDA, Seoul, South Korea, 1995.

[52] S. Hirano, C. Itakura, H. Seino et al., "Chitosan as an ingredient for domestic animal feeds," Journal of Agricultural and Food Chemistry, vol. 38, no. 5, pp. 1214-1217, 1990.

[53] S.I. J. Allwin, K. I. Jeyasanta, and J. Patterson, "Extraction of chitosan from White Shrimp (Litopenaeus vannamei) processing waste and examination of its bioactive potentials," Advances in Biological Research, vol. 9, no. 6, pp. 389-396, 2015.

[54] M. H. Uriarte-Montoya, J. L. Arias-Moscoso, M. PlascenciaJatomea et al., "Jumbo squid (Dosidicus gigas) mantle collagen: extraction, characterization, and potential application in the preparation of chitosan-collagen biofilms," Bioresource Technology, vol. 101, no. 11, pp. 4212-4219, 2010.

[55] X.-G. Chen, L. Zheng, Z. Wang, C.-Y. Lee, and H.-J. Park, "Molecular affinity and permeability of different molecular weight chitosan membranes," Journal of Agricultural and Food Chemistry, vol. 50, no. 21, pp. 5915-5918, 2002.

[56] K. Nadarajah, W. Prinyawiwatkul, H. K. No, S. Sathivel, and Z. $\mathrm{Xu}$, "Sorption behavior of crawfish chitosan films as affected by chitosan extraction processes and solvent types," Journal of Food Science, vol. 71, no. 2, pp. E33-E39, 2006.

[57] Y. Xing, Q. Xu, S. X. Yang et al., "Preservation mechanism of chitosan-Based coating with cinnamon oil for fruits storage based on sensor data," Sensors, vol. 16, no. 7, p. 1111, 2016.

[58] D. Knorr, "Dye binding properties of chitin and chitosan," Journal of Food Science, vol. 48, no. 1, pp. 36-37, 1983.

[59] S. F. Chou, J. Y. Lai, C. H. Cho, and C. H. Lee, "Relationships between surface roughness/stiffness of chitosan coatings and fabrication of corneal keratocyte spheroids: effect of degree of deacetylation," Colloids and Surfaces B: Biointerfaces, vol. 142, pp. 105-113, 2016.

[60] G. I. Olivas and G. V. Barbosa-Cánovas, "Edible coatings for fresh-cut fruits," Critical Reviews in Food Science and Nutrition, vol. 45 , no. 7-8, pp. 657-670, 2005.

[61] F. Devlieghere, A. Vermeulen, and J. Debevere, "Chitosan: antimicrobial activity, interactions with food components and applicability as a coating on fruit and vegetables," Food Microbiology, vol. 21, no. 6, pp. 703-714, 2004.

[62] G.-J. Tsai, W.-H. Su, H.-C. Chen, and C.-L. Pan, "Antimicrobial activity of shrimp chitin and chitosan from different treatments and applications of fish preservation," Fisheries Science, vol. 68, no. 1, pp. 170-177, 2002.

[63] H. K. No, S. D. Kim, W. Prinyawiwatkul, and S. P. Meyers, "Growth of soybean sprouts affected by chitosans prepared under various deproteinization and demineralization times," Journal of the Science of Food and Agriculture, vol. 86, no. 13, pp. 65-70, 2006.

[64] J. Li, Y. Wu, and L. Zhao, "Antibacterial activity and mechanism of chitosan with ultra high molecular weight," Carbohydrate Polymers, vol. 148, pp. 200-205, 2016.

[65] L. Qi, Z. Xu, X. Jiang, C. Hu, and X. Zou, "Preparation and antibacterial activity of chitosan nanoparticles," Carbohydrate Research, vol. 339, no. 16, pp. 2693-2700, 2004. 
[66] M. Ganan, A. V. Carrascosa, and A. J. Martínez-Rodríguez, "Antimicrobial activity of chitosan against Campylobacter spp. and other microorganisms and its mechanism of action," Journal of Food Protection, vol. 72, no. 8, pp. 1735-1738, 2009.

[67] M.-M. Lou, B. Zhu, I. Muhammad et al., "Antibacterial activity and mechanism of action of chitosan solutions against apricot fruit rot pathogen Burkholderia seminalis," Carbohydrate Research, vol. 346, no. 11, pp. 1294-1301, 2011.

[68] B. Han, Y. Wei, X. Jia, J. Xu, and G. Li, "Correlation of the structure, properties, and antimicrobial activity of a soluble thiolated chitosan derivative," Journal of Applied Polymer Science, vol. 125, no. 2, pp. E143-E148, 2012.

[69] T. Ristić, S. Lasič, I. Kosalec, M. Bračič, and L. Fras-Zemljič, "The effect of chitosan nanoparticles onto Lactobacillus cells," Reactive and Functional Polymers, vol. 97, pp. 56-62, 2015.

[70] A. R. Madureira, A. Pereira, P. M. Castro, and M. Pintado, "Production of antimicrobial chitosan nanoparticles against food pathogens," Journal of Food Engineering, vol. 167, pp. 210216, 2015.

[71] Q. Wang, J.-H. Zuo, Q. Wang, Y. Na, and L.-P. Gao, "Inhibitory effect of chitosan on growth of the fungal phytopathogen, Sclerotinia sclerotiorum, and sclerotinia rot of carrot," Journal of Integrative Agriculture, vol. 14, no. 4, pp. 691-697, 2015.

[72] M. Kaya, M. Asan-Ozusaglam, and S. Erdogan, "Comparison of antimicrobial activities of newly obtained low molecular weight scorpion chitosan and medium molecular weight commercial chitosan," Journal of Bioscience and Bioengineering, vol. 121, no. 6, pp. 678-684, 2016.

[73] A. Mohammadi, M. Hashemi, and S. M. Hosseini, "Effect of chitosan molecular weight as micro and nanoparticles on antibacterial activity against some soft rot pathogenic bacteria," LWT-Food Science and Technology, vol. 71, pp. 347-355, 2016.

[74] N. Sayari, A. Sila, B. E. Abdelmalek et al., "Chitin and chitosan from the Norway lobster by-products: antimicrobial and anti-proliferative activities," International Journal of Biological Macromolecules, vol. 87, pp. 163-171, 2016.

[75] R. C. Goy, S. T. B. Morais, and O. B. G. Assis, "Evaluation of the antimicrobial activity of chitosan and its quaternized derivative on E. Coli and S. aureus growth," Revista Brasileira de Farmacognosia, vol. 26, no. 1, pp. 122-127, 2016.

[76] M. B. Vásconez, S. K. Flores, C. A. Campos, J. Alvarado, and L. N. Gerschenson, "Antimicrobial activity and physical properties of chitosan-tapioca starch based edible films and coatings," Food Research International, vol. 42, no. 7, pp. 762-769, 2009.

[77] C. Xiao, L. Zhu, W. Luo, X. Song, and Y. Deng, "Combined action of pure oxygen pretreatment and chitosan coating incorporated with rosemary extracts on the quality of fresh-cut pears," Food Chemistry, vol. 121, no. 4, pp. 1003-1009, 2010.

[78] I. C. D. Guerra, P. D. L. de Oliveira, A. L. de Souza Pontes et al., "Coatings comprising chitosan and Mentha piperita L. or Mentha $\times$ villosa Huds essential oils to prevent common postharvest mold infections and maintain the quality of cherry tomato fruit," International Journal of Food Microbiology, vol. 214, pp. 168-178, 2015.

[79] J. Hafsa, M. a. Smach, M. R. Ben Khedher et al., "Physical, antioxidant and antimicrobial properties of chitosan films containing Eucalyptus globulus essential oil," LWT_Food Science and Technology, vol. 68, pp. 356-364, 2016.

[80] Q. Ma, Y. Zhang, and Q. Zhong, "Physical and antimicrobial properties of chitosan films incorporated with lauric arginate, cinnamon oil, and ethylenediaminetetraacetate," LWT-Food Science and Technology, vol. 65, pp. 173-179, 2016.
[81] H. Qi, W. Hu, A. Jiang, M. Tian, and Y. Li, "Extending shelflife of Fresh-cut 'Fuji' apples with chitosan-coatings," Innovative Food Science and Emerging Technologies, vol. 12, no. 1, pp. 62-66, 2011.

[82] C. E. Ochoa-Velasco and J. Á. Guerrero-Beltrán, "Postharvest quality of peeled prickly pear fruit treated with acetic acid and chitosan," Postharvest Biology and Technology, vol. 92, pp. 139145,2014

[83] Y. Zhang, M. Zhang, and H. Yang, "Postharvest chitosan-gsalicylic acid application alleviates chilling injury and preserves cucumber fruit quality during cold storage," Food Chemistry, vol. 174, pp. 558-563, 2015.

[84] Y. Xing, X. Li, L. Zhang et al., "Effect of $\mathrm{TiO}_{2}$ nanoparticles on the antibacterial and physical properties of polyethylene-based film," Progress in Organic Coatings, vol. 73, no. 2-3, pp. 219-224, 2012.

[85] G. D. Jovanović, A. S. Klaus, and M. P. Nikšić, "Antimicrobial activity of chitosan coatings and films against Listeria monocytogenes on black radish," Revista Argentina de Microbiología, vol. 48, no. 2, pp. 128-136, 2016.

[86] Z. Flores, D. S. Martín, R. Villalobos-Carvajal, G. TabiloMunizaga, F. Osorio, and J. Leiva-Veg, "Physicochemical characterization of chitosan-based coating-forming emulsions: effect of homogenization method and carvacrol content," Food Hydrocolloids, vol. 61, pp. 851-857, 2016.

[87] U. Latif, K. Al-Rubeaan, and A. T. M. Saeb, "A review on antimicrobial chitosan-silver nanocomposites: a roadmap toward pathogen targeted synthesis," International Journal of Polymeric Materials and Polymeric Biomaterials, vol. 64, no. 9, pp. 448458, 2015.

[88] S. Shi, W. Wang, L. Liu, S. Wu, Y. Wei, and W. Li, "Effect of chitosan/nano-silica coating on the physicochemical characteristics of longan fruit under ambient temperature," Journal of Food Engineering, vol. 118, no. 1, pp. 125-131, 2013.

[89] H. Song, W. Yuan, P. Jin et al., "Effects of chitosan/nano-silica on postharvest quality and antioxidant capacity of loquat fruit during cold storage," Postharvest Biology and Technology, vol. 119, pp. 41-48, 2016.

[90] E. Velickova, E. Winkelhausen, S. Kuzmanova, V. D. Alves, and M. Moldão-Martins, "Impact of chitosan-beeswax edible coatings on the quality of fresh strawberries (Fragaria ananassa cv Camarosa) under commercial storage conditions," LWTFood Science and Technology, vol. 52, no. 2, pp. 80-92, 2013.

[91] S.-L. Li, J. Lin, and X.-M. Chen, "Effect of chitosan molecular weight on the functional properties of chitosan-maltose Maillard reaction products and their application to fresh-cut Typha latifolia L," Carbohydrate Polymers, vol. 102, no. 1, pp. 682-690, 2014.

[92] M. Sabaghi, Y. Maghsoudlou, M. Khomeiri, and A. M. Ziaiifar, "Active edible coating from chitosan incorporating green tea extract as an antioxidant and antifungal on fresh walnut kernel," Postharvest Biology and Technology, vol. 110, pp. 224-228, 2015.

[93] J. M. Vieira, M. L. Flores-López, D. J. de Rodríguez, M. C. Sousa, A. A. Vicente, and J. T. Martins, "Effect of chitosan-Aloe vera coating on postharvest quality of blueberry (Vaccinium corymbosum) fruit," Postharvest Biology and Technology, vol. 116, pp. 88-97, 2016.

[94] I. Khalifa, H. Barakat, H. A. El-Mansy, and S. A. Soliman, "Enhancing the keeping quality of fresh strawberry using chitosan-incorporated olive processing wastes," Food Bioscience, vol. 13, pp. 69-75, 2016. 
[95] R. P. Carlson, R. Taffs, W. M. Davison, and P. S. Stewart, "Anti-biofilm properties of chitosan-coated surfaces," Journal of Biomaterials Science, Polymer Edition, vol. 19, no. 8, pp. 10351046, 2008.

[96] J. Gómez-Estaca, A. López de Lacey, M. E. López-Caballero, M. C. Gómez-Guillén, and P. Montero, "Biodegradable gelatinchitosan films incorporated with essential oils as antimicrobial agents for fish preservation," Food Microbiology, vol. 27, no. 7, pp. 889-896, 2010.

[97] N. S. Bedel, M. Tezcan, O. Ceylan, G. Gurdag, and H. Cicek, "Effects of pore morphology and size on antimicrobial activity of chitosan/poly(ethylene glycol) diacrylate macromer semiIPN hydrogels," Journal of Applied Polymer Science, vol. 132, no. 43, Article ID 42707, 2015.

[98] A. N. Azevedo, P. R. Buarque, E. M. O. Cruz et al., "Response surface methodology for optimisation of edible chitosan coating formulations incorporating essential oil against several foodborne pathogenic bacteria," Food Control, vol. 43, pp. 1-9, 2014.

[99] T. P. Singh, M. K. Chatli, and J. Sahoo, "Development of chitosan based edible films: process optimization using response surface methodology," Journal of Food Science and Technology, vol. 52, no. 5, pp. 2530-2543, 2015.

[100] Y. Andres, L. Giraud, C. Gerente, and P. Le Cloirec, "Antibacterial effects of chitosan powder: mechanisms of action," Environmental Technology, vol. 28, no. 12, pp. 1357-1363, 2007.

[101] L. M. Bravo-Anaya, J. F. A. Soltero, and M. Rinaudo, "DNA/chitosan electrostatic complex," International Journal of Biological Macromolecules, vol. 88, pp. 345-353, 2016.

[102] I. M. Helander, E.-L. Nurmiaho-Lassila, R. Ahvenainen, J. Rhoades, and S. Roller, "Chitosan disrupts the barrier properties of the outer membrane of Gram-negative bacteria," International Journal of Food Microbiology, vol. 71, no. 2-3, pp. 235-244, 2001.

[103] M. Friedman, "Overview of antibacterial, antitoxin, antiviral, and antifungal activities of tea flavonoids and teas," Molecular Nutrition and Food Research, vol. 51, no. 1, pp. 116-134, 2007.

[104] T. W. Sirk, E. F. Brown, A. K. Sum, and M. Friedman, "Molecular dynamics study on the biophysical interactions of seven green tea catechins with lipid bilayers of cell membranes," Journal of Agricultural and Food Chemistry, vol. 56, no. 17, pp. 7750-7758, 2008.

[105] D. Raafat, K. Von Bargen, A. Haas, and H.-G. Sahl, "Insights into the mode of action of chitosan as an antibacterial compound," Applied and Environmental Microbiology, vol. 74, no. 12, pp. 3764-3773, 2008.

[106] J. Knowles and S. Roller, "Efficacy of chitosan, carvacrol, and a hydrogen peroxide-based biocide against foodborne microorganisms in suspension and adhered to stainless steel," Journal of Food Protection, vol. 64, no. 10, pp. 1542-1548, 2001.

[107] K. Fisher and C. Phillips, "Potential antimicrobial uses of essential oils in food: is citrus the answer?" Trends in Food Science and Technology, vol. 19, no. 3, pp. 156-164, 2008.

[108] C. Q. Qin, H. R. Li, Q. Xiao, Y. Liu, J. C. Zhu, and Y. M. $\mathrm{Du}$, "Water-solubility of chitosan and its antimicrobial activity," Carbohydrate Polymers, vol. 63, no. 3, pp. 367-374, 2006.

[109] K. K. Kuorwel, M. J. Cran, K. Sonneveld, J. Miltz, and S. W. Bigger, "Essential oils and their principal constituents as antimicrobial agents for synthetic packaging films," Journal of Food Science, vol. 76, no. 9, pp. R164-R177, 2011.

[110] Y. Xing, X. Li, Q. Xu, Y. Jiang, J. Yun, and W. Li, "Effects of chitosan-based coating and modified atmosphere packaging
(MAP) on browning and shelf life of fresh-cut lotus root (Nelumbo nucifera Gaerth)," Innovative Food Science and Emerging Technologies, vol. 11, no. 4, pp. 684-689, 2010.

[111] Z. Xiao, Y. Luo, Y. Luo, and Q. Wang, "Combined effects of sodium chlorite dip treatment and chitosan coatings on the quality of fresh-cut d'Anjou pears," Postharvest Biology and Technology, vol. 62, no. 3, pp. 319-326, 2011.

[112] X. F. Shao, K. Tu, S. Tu, and J. Tu, "A Combination of heat treatment and chitosan coating delays ripening and reduces decay in 'Gala' apple fruit," Journal of Food Quality, vol. 35, no. 2, pp. 83-92, 2012.

[113] X. Sun, Z. Wang, H. Kadouh, and K. Zhou, "The antimicrobial, mechanical, physical and structural properties of chitosangallic acid films," LWT-Food Science and Technology, vol. 57, no. 1, pp. 83-89, 2014.

[114] A. Gennadios, Protein-Based Films and Coatings, CRC Press, 2002.

[115] Y. Zhao, K. Tu, J. Su et al., "Heat treatment in combination with antagonistic yeast reduces diseases and elicits the active defense responses in harvested cherry tomato fruit," Journal of Agricultural and Food Chemistry, vol. 57, no. 16, pp. 7565-7570, 2009.

[116] B. Lin, Y. Du, X. Liang, X. Wang, X. Wang, and J. Yang, "Effect of chitosan coating on respiratory behavior and quality of stored litchi under ambient temperature," Journal of Food Engineering, vol. 102, no. 1, pp. 94-99, 2011.

[117] P. Gao, Z. Zhu, and P. Zhang, "Effects of chitosan-glucose complex coating on postharvest quality and shelf life of table grapes," Carbohydrate Polymers, vol. 95, no. 1, pp. 371-378, 2013.

[118] K. Liu, J. Liu, H. Li, C. Yuan, J. Zhong, and Y. Chen, "Influence of postharvest citric acid and chitosan coating treatment on ripening attributes and expression of cell wall related genes in cherimoya (Annona cherimola Mill.) fruit," Scientia Horticulturae, vol. 198, pp. 1-11, 2016.

[119] H. Gao, Z. K. Zhang, H. K. Chai et al., "Melatonin treatment delays postharvest senescence and regulates reactive oxygen species metabolism in peach fruit," Postharvest Biology and Technology, vol. 118, pp. 103-110, 2016.

[120] M. E. I. Badawy and E. I. Rabea, "Potential of the biopolymer chitosan with different molecular weights to control postharvest gray mold of tomato fruit," Postharvest Biology and Technology, vol. 51, no. 1, pp. 110-117, 2009.

[121] H. Tomida, T. Fujii, N. Furutani et al., "Antioxidant properties of some different molecular weight chitosans," Carbohydrate Research, vol. 344, no. 13, pp. 1690-1696, 2009.

[122] K. Hong, J. Xie, L. Zhang, D. Sun, and D. Gong, "Effects of chitosan coating on postharvest life and quality of guava (Psidium guajava L.) fruit during cold storage," Scientia Horticulturae, vol. 144, pp. 172-178, 2012.

[123] F. Sousa, G. M. Guebitz, and V. Kokol, "Antimicrobial and antioxidant properties of chitosan enzymatically functionalized with flavonoids," Process Biochemistry, vol. 44, no. 7, pp. 749756, 2009.

[124] K. Liu, C. Yuan, Y. Chen, H. Li, and J. Liu, "Combined effects of ascorbic acid and chitosan on the quality maintenance and shelf life of plums," Scientia Horticulturae, vol. 176, pp. 45-53, 2014.

[125] M. D. C. Antunes, S. Dandlen, A. M. Cavaco, and G. Miguel, "Effects of postharvest application of 1-MCP and postcutting dip treatment on the quality and nutritional properties of fresh-cut kiwifruit," Journal of Agricultural and Food Chemistry, vol. 58, no. 10, pp. 6173-6181, 2010. 
[126] E. Choe and D. B. Min, "Chemistry and reactions of reactive oxygen species in foods," Journal of Food Science, vol. 70, no. 9, pp. R142-R159, 2005.

[127] G. Kerch and V. Korkhov, "Effect of storage time and temperature on structure, mechanical and barrier properties of chitosan-based films," European Food Research and Technology, vol. 232, no. 1, pp. 17-22, 2011.

[128] E. Poverenov, Y. Zaitsev, H. Arnon et al., "Effects of a composite chitosan-gelatin edible coating on postharvest quality and storability of red bell peppers," Postharvest Biology and Technology, vol. 96, pp. 106-109, 2014.

[129] A. Giannakas, K. Grigoriadi, A. Leontiou, N.-M. Barkoula, and A. Ladavos, "Preparation, characterization, mechanical and barrier properties investigation of chitosan-clay nanocomposites," Carbohydrate Polymers, vol. 108, no. 1, pp. 103-111, 2014.

[130] Y. Kasirga, A. Oral, and C. Caner, "Preparation and characterization of chitosan/montmorillonite-K10 nanocomposites films for food packaging applications," Polymer Composites, vol. 33, no. 11, pp. 1874-1882, 2012.

[131] M. Pereda, A. Dufresne, M. I. Aranguren, and N. E. Marcovich, "Polyelectrolyte films based on chitosan/olive oil and reinforced with cellulose nanocrystals," Carbohydrate Polymers, vol. 101, no. 1, pp. 1018-1026, 2014.

[132] M. Pereda, G. Amica, and N. E. Marcovich, "Development and characterization of edible chitosan/olive oil emulsion films," Carbohydrate Polymers, vol. 87, no. 2, pp. 1318-1325, 2012.

[133] V. C. Souza, M. L. Monte, and L. A. A. Pinto, "Effect of carp (Cyprinus carpio) oil incorporation on water vapour permeability, mechanical properties and transparency of chitosan films," International Journal of Food Science and Technology, vol. 48, no. 6, pp. 1309-1317, 2013.

[134] Z.-H. Zhang, Y.-Y. Qin, J. Fan, T.-R. Zhao, and C.-S. Cheng, "Physical properties and antibacterial activity of a chitosan film incorporated with lavender essential oil," Advanced Materials Research, vol. 706-708, pp. 197-200, 2013.

[135] S. N. Adila, N. E. Suyatma, A. S. Firlieyanti, and A. Bujang, "Antimicrobial and physical properties of chitosan film as affected by solvent types and glycerol as plasticizer," Advanced Materials Research, vol. 748, pp. 155-159, 2013.

[136] S.-Y. Cheng, B.-J. Wang, and Y.-M. Weng, "Antioxidant and antimicrobial edible zein/chitosan composite films fabricated by incorporation of phenolic compounds and dicarboxylic acids," LWT-Food Science and Technology, vol. 63, no. 1, pp. 115-121, 2015.

[137] S. M. Ojagh, M. Rezaei, S. H. Razavi, and S. M. H. Hosseini, "Development and evaluation of a novel biodegradable film made from chitosan and cinnamon essential oil with low affinity toward water," Food Chemistry, vol. 122, no. 1, pp. 161-166, 2010.

[138] P.-J. Chien, F. Sheu, and H.-R. Lin, "Quality assessment of low molecular weight chitosan coating on sliced red pitayas," Journal of Food Engineering, vol. 79, no. 2, pp. 736-740, 2007.

[139] D. Sun, G. Liang, J. Xie, X. Lei, and Y. Mo, "Improved preservation effects of litchi fruit by combining chitosan coating with ascorbic acid treatment during postharvest storage," African Journal of Biotechnology, vol. 9, no. 22, pp. 3272-3279, 2010.

[140] A. Saxena, T. M. Saxena, P. S. Raju, and A. S. Bawa, "Effect of controlled atmosphere storage and chitosan coating on quality of fresh-cut jackfruit bulbs," Food and Bioprocess Technology, vol. 6, no. 8, pp. 2182-2189, 2013.

[141] X.-H. Kou, W.-L. Guo, R.-Z. Guo, X.-Y. Li, and Z.-H. Xue, "Effects of chitosan, calcium chloride, and pullulan coating treatments on antioxidant activity in pear cv. 'Huang guan' during storage," Food and Bioprocess Technology, vol. 7, no. 3, pp. 671-681, 2014.

[142] C. Han, J. Zuo, Q. Wang et al., "Effects of chitosan coating on postharvest quality and shelf life of sponge gourd ( $L u f f a$ cylindrica) during storage," Scientia Horticulturae, vol. 166, pp. $1-8,2014$.

[143] E. E. El-Eleryan, "Effect of chitosan and green tea on the quality of Washington Navel orange during cold storage," American Journal of Plant Physiology, vol. 10, no. 1, pp. 43-54, 2015.

[144] S. M. Ibrahim, S. Nahar, J. M. Islam et al., "Effect of low molecular weight chitosan coating on physico-chemical properties and shelf life extension of pineapple (Ananas sativus)," Journal of Forest Products and Industries, vol. 3, no. 3, pp. 161-166, 2014.

[145] N. Suseno, E. Savitri, L. Sapei, and K. S. Padmawijaya, "Improving shelf-life of cavendish banana using chitosan edible coating," Procedia Chemistry, vol. 9, pp. 113-120, 2014.

[146] M. Plainsirichai, S. Leelaphatthanapanich, and N. Wongsachai, "Effect of chitosan on the quality of rose apples (Syzygium agueum Alston) cv. Tabtim Chan stored at an ambient temperature," APCBEE Procedia, vol. 8, pp. 317-322, 2014.

[147] M. Petriccione, F. De Sanctis, M. S. Pasquariello et al., "The effect of chitosan coating on the quality and nutraceutical traits of sweet cherry during postharvest life," Food and Bioprocess Technology, vol. 8, no. 2, pp. 394-408, 2015.

[148] M. Petriccione, F. Mastrobuoni, M. S. Pasquariello et al., "Effect of chitosan coating on the postharvest quality and antioxidant enzyme system response of strawberry fruit during cold storage," Foods, vol. 4, no. 4, pp. 501-523, 2015.

[149] N. B. Gol, M. L. Chaudhari, and T. V. R. Rao, "Effect of edible coatings on quality and shelf life of carambola (Averrhoa carambola L.) fruit during storage," Journal of Food Science \& Technology, vol. 52, no. 1, pp. 78-91, 2015.

[150] Z. S. Luo, X. L. Xu, T. Q. Xu, and J. Xie, "Effect of chitosan coating with nano- $\mathrm{CaCO}_{3}$ appendix on quality of fresh cut yam," Transactions of the Chinese Society for Agricultural Machinery, vol. 40, no. 4, pp. 125-128, 2009.

[151] S. Zhang, Y. Yu, C. Xiao, X. Wang, and Y. Lei, "Effect of ultraviolet irradiation combined with chitosan coating on preservation of jujube under ambient temperature," LWT_Food Science and Technology, vol. 57, no. 2, pp. 749-754, 2014.

[152] Z. Ban, W. Wei, X. Yang, J. Feng, J. Guan, and L. Li, "Combination of heat treatment and chitosan coating to improve postharvest quality of wolfberry (Lycium barbarum)," International Journal of Food Science and Technology, vol. 50, no. 4, pp. 1019-1025, 2015.

[153] M. P. Souza, A. F. M. Vaz, M. A. Cerqueira, J. A. Texeira, A. A. Vicente, and M. G. Carneiro-da-Cunha, "Effect of an edible nanomultilayer coating by electrostatic self-assembly on the shelf life of fresh-cut mangoes," Food and Bioprocess Technology, vol. 8, no. 3, pp. 647-654, 2014.

[154] B. G. S. Medeiros, A. C. Pinheiro, M. G. Carneiro-da-Cunha, and A. A. Vicente, "Development and characterization of a nanomultilayer coating of pectin and chitosan-evaluation of its gas barrier properties and application on 'Tommy Atkins' mangoes," Journal of Food Engineering, vol. 110, no. 3, pp. 457464, 2012.

[155] M. Cissé, J. Polidori, D. Montet, G. Loiseau, and M. N. DucampCollin, "Preservation of mango quality by using functional chitosan-lactoperoxidase systems coatings," Postharvest Biology and Technology, vol. 101, pp. 10-14, 2015. 
[156] W. Waewthongrak, S. Pisuchpen, and W. Leelasuphakul, "Effect of Bacillus subtilis and chitosan applications on green mold (Penicilium digitatum Sacc.) decay in citrus fruit," Postharvest Biology and Technology, vol. 99, pp. 44-49, 2015.

[157] J. X. Chong, S. Lai, and H. Yang, "Chitosan combined with calcium chloride impacts fresh-cut honeydew melon by stabilising nanostructures of sodium-carbonate-soluble pectin," Food Control, vol. 53, pp. 195-205, 2015.

[158] M. Duran, M. S. Aday, N. N. D. Zorba, R. Temizkan, M. B. Büyükcan, and C. Caner, "Potential of antimicrobial active packaging 'containing natamycin, nisin, pomegranate and grape seed extract in chitosan coating' to extend shelf life of fresh strawberry," Food and Bioproducts Processing, vol. 98, pp. 354-363, 2016.

[159] S. Y. Wang and H. Gao, "Effect of chitosan-based edible coating on antioxidants, antioxidant enzyme system, and postharvest fruit quality of strawberries (Fragaria x aranassa Duch.)," LWT-Food Science and Technology, vol. 52, no. 2, pp. 71-79, 2013.

[160] Y. Zhou, L. Zhang, and K. Zeng, "Efficacy of Pichia membranaefaciens combined with chitosan against Colletotrichum gloeosporioides in citrus fruits and possible modes of action," Biological Control, vol. 96, pp. 39-47, 2016.

[161] G. Yang, J. Yue, X. Gong et al., "Blueberry leaf extracts incorporated chitosan coatings for preserving postharvest quality of fresh blueberries," Postharvest Biology and Technology, vol. 92, pp. 46-53, 2014.

[162] X. Sun, J. Narciso, Z. Wang, C. Ference, J. Bai, and K. Zhou, "Effects of chitosan-essential oil coatings on safety and quality of fresh blueberries," Journal of Food Science, vol. 79, no. 5, pp. M955-M960, 2014.

[163] L. Abugoch, C. Tapia, D. Plasencia et al., "Shelf-life of fresh blueberries coated with quinoa protein/chitosan/sunflower oil edible film," Journal of the Science of Food and Agriculture, vol. 96, no. 2, pp. 619-626, 2016.

[164] V. Chiabrando and G. Giacalone, "Anthocyanins, phenolics and antioxidant capacity after fresh storage of blueberry treated with edible coatings," International Journal of Food Sciences and Nutrition, vol. 66, no. 3, pp. 248-253, 2015.

[165] R. L. Carvalho, M. F. Cabral, T. A. Germano et al., "Chitosan coating with trans-cinnamaldehyde improves structural integrity and antioxidant metabolism of fresh-cut melon," Postharvest Biology and Technology, vol. 113, pp. 29-39, 2016.

[166] R. Pushkala, P. K. Raghuram, and N. Srividya, "Chitosan based powder coating technique to enhance phytochemicals and shelf life quality of radish shreds," Postharvest Biology and Technology, vol. 86, pp. 402-408, 2013.

[167] M. V. Alvarez, A. G. Ponce, and M. D. R. Moreira, "Antimicrobial efficiency of chitosan coating enriched with bioactive compounds to improve the safety of fresh cut broccoli," $L W T$ Food Science and Technology, vol. 50, no. 1, pp. 78-87, 2013.

[168] M. A. Mustafa, A. Ali, S. Manickam, and Y. Siddiqui, "Ultrasound-assisted chitosan-surfactant nanostructure assemblies: towards maintaining postharvest quality of tomatoes," Food and Bioprocess Technology, vol. 7, no. 7, pp. 2102-2111, 2014.

[169] A. Saha, R. K. Gupta, and Y. K. Tyagi, "Effects of edible coatings on the shelf life and quality of potato (Solanum tuberosum L.) tubers during storage," Journal of Chemical and Pharmaceutical Research, vol. 6, no. 12, pp. 802-809, 2014.

[170] J. Chen, X. Zou, Q. Liu, F. Wang, W. Feng, and N. Wan, “Combination effect of chitosan and methyl jasmonate on controlling
Alternaria alternata and enhancing activity of cherry tomato fruit defense mechanisms," Crop Protection, vol. 56, pp. 31-36, 2014.

[171] H. Yang, J. Zheng, C. Huang, X. Zhao, H. Chen, and Z. Sun, "Effects of combined aqueous chlorine dioxide and chitosan coatings on microbial growth and quality maintenance of freshcut bamboo shoots (Phyllostachys praecox $\mathrm{f}$. prevernalis.) during storage," Food and Bioprocess Technology, vol. 8, no. 5, pp. 10111019, 2015.

[172] A. D. N. Simões, J. A. Tudela, A. Allende, R. Puschmann, and M. I. Gil, "Edible coatings containing chitosan and moderate modified atmospheres maintain quality and enhance phytochemicals of carrot sticks," Postharvest Biology and Technology, vol. 51, no. 3, pp. 364-370, 2009.

[173] R. Pushkala, K. R. Parvathy, and N. Srividya, "Chitosan powder coating, a novel simple technique for enhancement of shelf life quality of carrot shreds stored in macro perforated LDPE packs," Innovative Food Science and Emerging Technologies, vol. 16, pp. 11-20, 2012.

[174] M. Qiu, C. Wu, G. Ren, X. Liang, X. Wang, and J. Huang, "Effect of chitosan and its derivatives as antifungal and preservative agents on postharvest green asparagus," Food Chemistry, vol. 155, pp. 105-111, 2014.

[175] M. Kong, X. G. Chen, K. Xing, and H. J. Park, "Antimicrobial properties of chitosan and mode of action: a state of the art review," International Journal of Food Microbiology, vol. 144, no. 1, pp. 51-63, 2010.

[176] M. Hosseinnejad and S. M. Jafari, "Evaluation of different factors affecting antimicrobial properties of chitosan," International Journal of Biological Macromolecules, vol. 85, pp. 467-475, 2016.

[177] J. Carneiro, J. Tedim, S. C. M. Fernandes et al., "Functionalized chitosan-based coatings for active corrosion protection," Surface and Coatings Technology, vol. 226, pp. 51-59, 2013. 

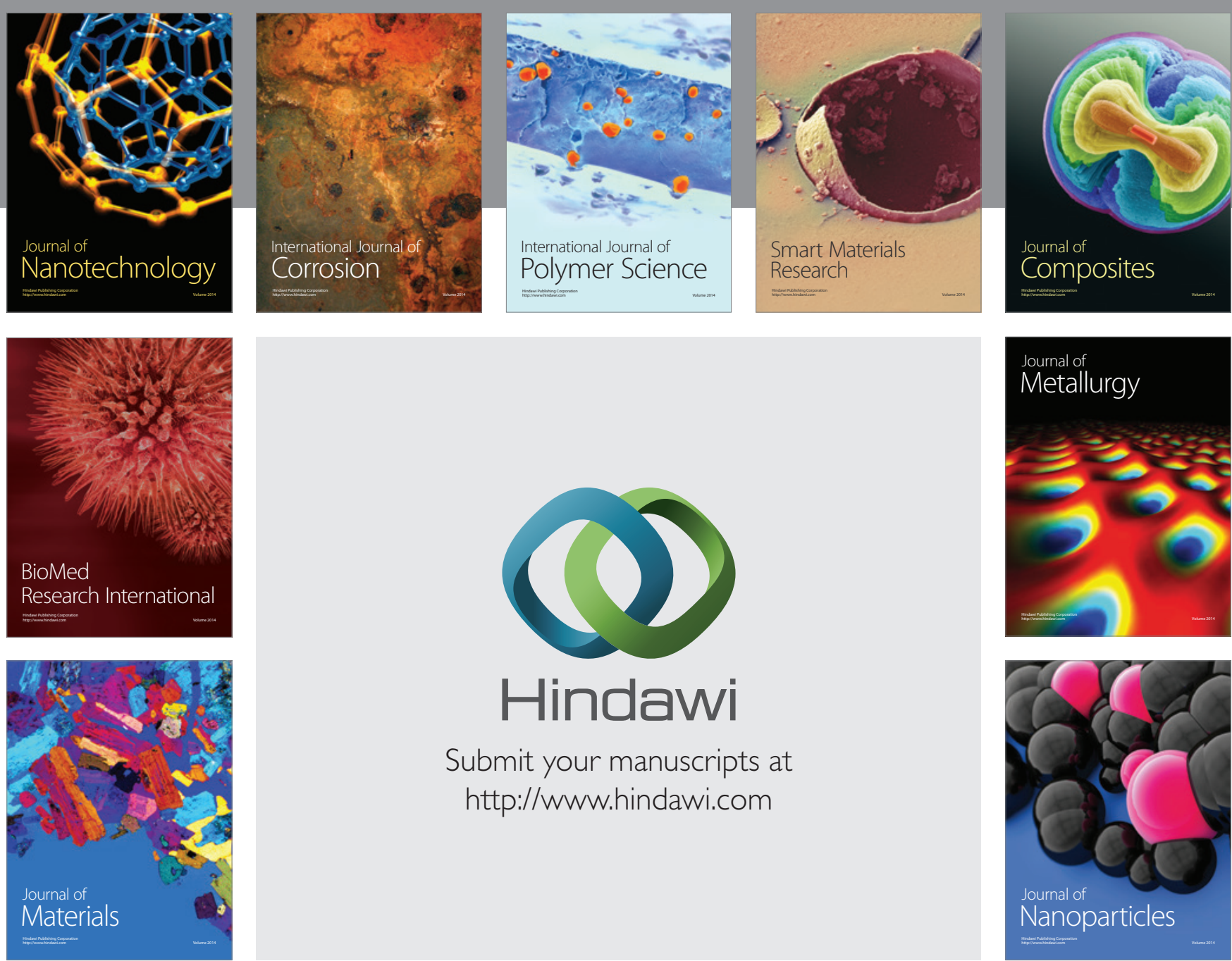

\section{Hindawi}

Submit your manuscripts at

http://www.hindawi.com

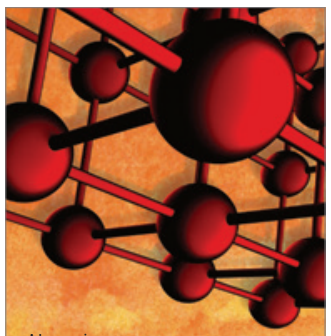

Materials Science and Engineering
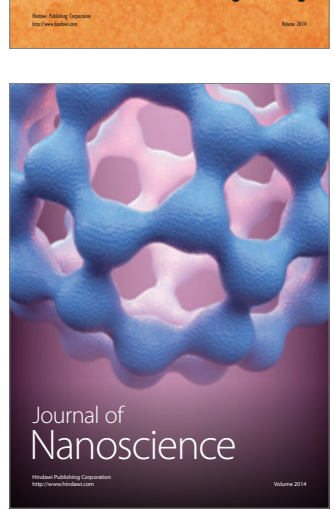
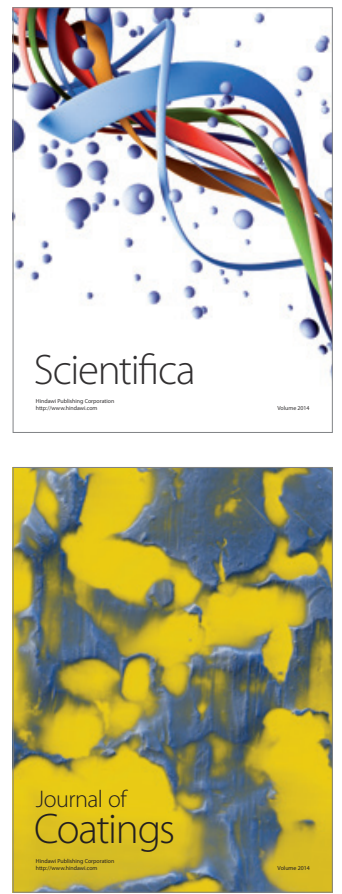
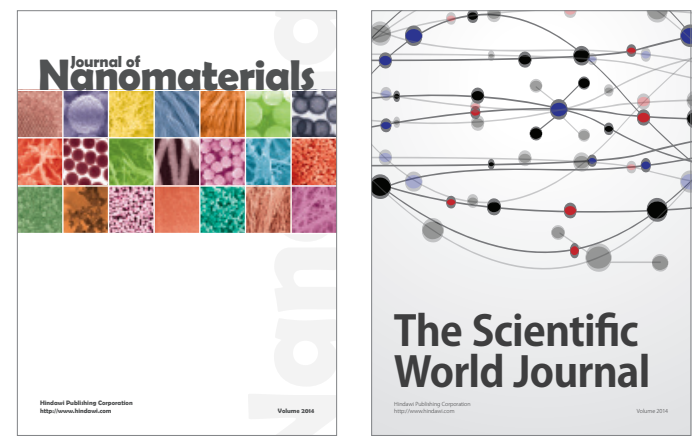

The Scientific World Journal
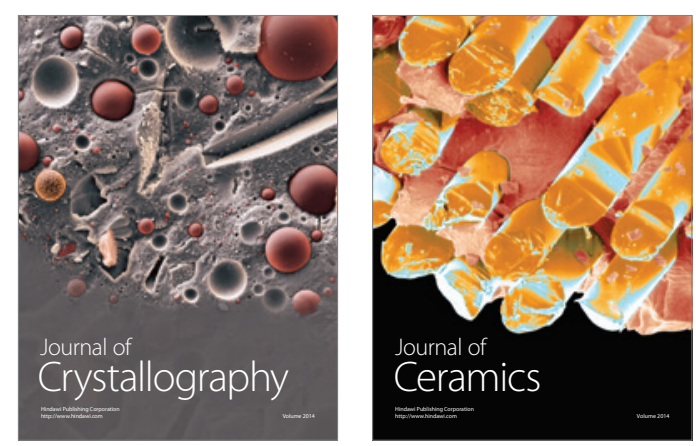
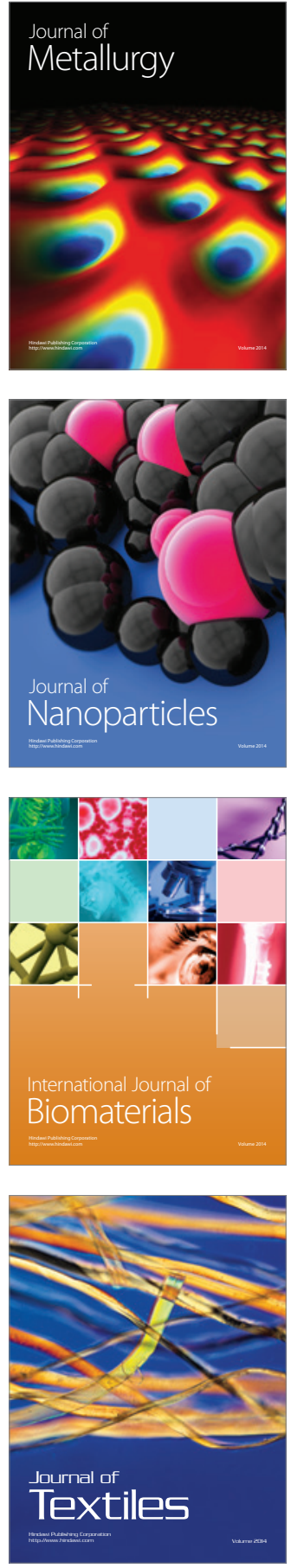